\begin{tabular}{|c|l|}
\hline Title & A bsorption and action spectra analysis of ammonium fluoride doped titania photocatalysts \\
\hline Author(s) & Dozzi, Maria V ittoria; Ohtani, Bunsho; Selli, Elena \\
\hline Citation & $\begin{array}{l}\text { Physical Chemistry Chemical Physics, 13(40), 18217-18227 } \\
\text { https://doi.org/10.1039/c1cp21558b }\end{array}$ \\
\hline Issue Date & 2011 \\
\hline Doc URL & http://hdl.handle.net/2115/48656 \\
\hline Rights & Phys. Chem. Chem. Phys., 2011, 13, 18217-18227- Reproduced by permission of the PCCP Owner Societies \\
\hline Type & article (author version) \\
\hline File Information & PCCP2011_Ohtani.pdf \\
\hline
\end{tabular}

Instructions for use 


\title{
Absorption and Action Spectra Analysis of Ammonium Fluoride-doped Titania Photocatalysts
}

\author{
Maria Vittoria Dozzi, ${ }^{a}$ Bunsho Ohtani $^{b}$ and Elena Selli* ${ }^{a}$ \\ ${ }^{a}$ Dipartimento di Chimica Fisica ed Elettrochimica, Università degli Studi di Milano, \\ via Golgi 19, I-20133 Milano, Italy \\ ${ }^{b}$ Catalysis Research Center, Hokkaido University, Sapporo 001-0021, Japan
}

\begin{abstract}
The photocatalytic behaviour of a series of ammonium fluoride $\left(\mathrm{NH}_{4} \mathrm{~F}\right)$ doped titania $\left(\mathrm{TiO}_{2}\right)$ photocatalysts has been investigated in the decomposition of acetic acid in aqueous suspension and in the gas phase mineralization of acetaldehyde. Very similar photoactivity trends, usually increasing with increasing the calcination temperature for a given nominal dopant amount, were obtained for the two test reactions. Moderately doped $\mathrm{TiO}_{2}$ calcined at $700{ }^{\circ} \mathrm{C}$, consisting of pure anatase, was the best performing photocatalyst in both reactions. In order to shed light on the origin of the enhanced photoactivity of such materials under visible light, acetic acid photooxidation was investigated systematically as a function of the irradiation wavelength, by collecting socalled action spectra. By comparing the shapes of the action spectra with those of the absorption spectra of the investigated photocatalysts a model is proposed, based on spectral features deconvolution, which allows a clear distinction between inactive light absorption, ascribed to nitrogen-doping, and effective photoactivity in acetic acid decomposition, possibly consequent to extrinsic absorption originated from surface oxygen vacancies or surface defects.
\end{abstract}




\section{Introduction}

Aiming at optimizing the photocatalytic performance of titania $\left(\mathrm{TiO}_{2}\right)$, the most active and suitable semiconductor photocatalyst, many efforts have been made in the last decade $^{1,2}$ in order to overcome one of its major drawbacks, i.e. its relatively large energy band gap (3.2 eV for anatase phase $\mathrm{e}^{3}$ ), which hampers the exploitation of solar light in photocatalytic reactions. Anion doping with p-block elements has been successfully pursued to sensitize $\mathrm{TiO}_{2}$ towards visible light, ${ }^{4,5}$ either by introducing newly created mid-gap energy states, or by narrowing the band gap itself. The effectiveness, but also the still not completely well understood nature of doping titanium dioxide with main group elements, such as $\mathrm{N},{ }^{4,6-13} \mathrm{C},{ }^{5,14-17} \mathrm{~B},{ }^{18-20} \mathrm{~S},{ }^{13,15,21-25} \mathrm{P},{ }^{26,27} \mathrm{I},{ }^{28,29}$ and $\mathrm{F}^{30-39}$ have been ascertained in a great number of studies, which also demonstrated that the insertion of dopant impurities in the oxide structure may increase the rate of undesired recombination of the photogenerated charge carriers. In contrast, the latter effect is known to become relatively lower, the higher is the crystallinity degree of the oxide structure.

Conflicting results have in particular been reported on the effects of fluorine $(F)$ as dopant element for $\mathrm{TiO}_{2},{ }^{30-39}$ most likely due to the different routes employed to prepare the doped materials and also to difficulties in the interpretation of photocatalytic results obtained with photocatalysts containing more than one dopant element, because of possible synergistic effects. ${ }^{34,39}$ In most cases F-doping apparently did not cause any appreciable shift of the fundamental band gap absorption edge of $\mathrm{TiO}_{2} \cdot{ }^{30,35,37}$ This is consistent with the theoretical band calculations, ${ }^{4,32}$ indicating that when $\mathrm{TiO}_{2}$ is doped with fluorine, localized high density energy levels, composed of $F 2 p$ states, reside below the valence band of $\mathrm{TiO}_{2}$. But, in spite of this, F-doped materials exhibit visiblelight-driven photoactivity, whose origin is still very uncertain. In fact, F atoms included 
in the semiconductor structure, thanks to their high electronegativity, could stabilize the electron release upon oxygen depletion during the calcination treatments. ${ }^{35,36}$ In this case visible light photo-excitation by extrinsic absorption bands of the so-generated oxygen vacancies can generate free charge carriers which could take part to surface chemical reactions. The enhanced photocatalytic activity of F-doped materials might also be related to the peculiar formation of $\mathrm{Ti}^{3+}$ centres, obtained by charge compensation effects consequent to the insertion of $\mathrm{F}^{-}$ions in the $\mathrm{O}^{2-}$ sites of the $\mathrm{TiO}_{2}$ lattice. $\mathrm{Ti}^{3+}$ surface states, forming a donor level just below the bottom of the conduction band of $\mathrm{TiO}_{2},{ }^{37}$ may efficiently trap photopromoted electrons and transfer them to $\mathrm{O}_{2}$ adsorbed on the $\mathrm{TiO}_{2}$ surface, thus decreasing the electron-hole recombination rate.

A systematic investigation has been recently performed by us on the photocatalytic activity under visible light of a series of doped $\mathrm{TiO}_{2}$ photocatalysts synthesized by the sol-gel method in the presence of different amounts of $\mathrm{NH}_{4} \mathrm{~F}$, as dopant source, and calcined at different temperature $\left(500-700{ }^{\circ} \mathrm{C}\right) .{ }^{40}$ The photoactivity of such materials in the degradation of formic acid in aqueous suspensions, employed as preliminary test reaction, was higher than that of undoped materials prepared by the same synthetic route. Of course, aiming at verifying the effective visible light activation of doped materials, the choice of an appropriate photocatalytic test reaction is crucial and the use of substrates able to absorb visible light and inject electrons into the semiconductor from their electronically excited state should be avoided. ${ }^{41}$

In the present work we explore the photocatalytic behaviour of an extended series of $\mathrm{NH}_{4} \mathrm{~F}$-doped $\mathrm{TiO}_{2}$ photocatalysts in two other reactions, i.e. the decomposition of acetic acid in aqueous suspension and the gas phase mineralization of acetaldehyde. Both substrates do not absorb visible light. In order to shed light on the origin of the 
enhanced photoactivity of such materials under visible light, the photooxidation of acetic acid was also investigated systematically as a function of the irradiation wavelength, by collecting so-called action spectra. This type of analysis, representing the most powerful photocatalytic characterization tool to determine the effective wavelength-dependent response and activity of a photocatalyst, ${ }^{41,42}$ has never been applied to similarly doped materials so far. By comparing the shapes of the action spectra with those of the absorption spectra of the investigated photocatalysts a model is proposed, which allows a clear distinction between light absorption and effective photoactivity as a function of the irradiation wavelength.

\section{Experimental Section}

\subsection{Doped- $\mathrm{TiO}_{2}$ preparation and characterization}

The series of doped titania $\left(\mathrm{D}-\mathrm{TiO}_{2}\right)$ photocatalysts was prepared by the sol-gel method in the presence of different amounts of $\mathrm{NH}_{4} \mathrm{~F}$, used as dopant source, and calcined at different temperature $\left(500-700{ }^{\circ} \mathrm{C}\right)$. The nominal dopant/Ti percent molar ratios were equal to 3, 5, 12 and 25. More details on the preparation of doped materials and on their characterization by XRD and BET analyses can be found elsewhere. ${ }^{40}$

XPS analysis was performed by a JEOL JPS-9010MC spectrometer with Mg Ka radiation, $10 \mathrm{eV}$ pass energy and $0.1 \mathrm{eV}$ energy step. The analysis area of the sample pellets was around $6 \mathrm{~mm}^{2}$, the depth about 1-2 $\mathrm{mm}$. The charging effect on the analysis was corrected considering the binding energy value of $\mathrm{C} 1 \mathrm{~s}$ at $284.7 \mathrm{eV}$, due to adventitious carbon. Quantification was obtained using the SPEC-SURF software provided by Jeol. Diffuse reflectance spectra of the photocatalysts powders were recorded on a Jasco V-670 spectrophotometer equipped with a PIN-757 integrating sphere, using barium sulphate as reference, and then converted into absorption spectra. 
The samples were labelled as D_(X)_(Y), with X referring to the nominal dopant/Ti percent molar ratio and $\mathrm{Y}$ to the calcination temperature in Celsius. Reference undoped materials, prepared by exactly the same synthetic route in the absence of $\mathrm{NH}_{4} \mathrm{~F}$, are referred as the D_0_(Y) photocatalysts series.

All reagents were purchased from Aldrich and employed as received. Water purified by a Milli-Q water system (Millipore) was used throughout.

\subsection{Acetic acid oxidative decomposition under polychromatic irradiation}

The photocatalytic tests were performed in a glass tube $(18 \mathrm{~mm}$ in inner diameter and $180 \mathrm{~mm}$ in length) with a $c a .35-\mathrm{mL}$ volume. Each photocatalyst powder (50 mg) was suspended in an aqueous solution $(5.0 \mathrm{~mL})$ containing $5.0 \mathrm{vol} . \%$ of acetic acid. This amount of photocatalyst powder in the suspension was high enough to ensure total light absorption. The glass tube was sealed with a double-capped rubber septum and Parafilm, to prevent leakage of gas and/or contamination during the runs.

The suspensions were irradiated using a 400-W high-pressure mercury lamp (Eikosha) under vigorous magnetic stirring (1000 rpm). The wavelength of light was $>290$ $\mathrm{nm}$, with an average emission intensity of $390 \mathrm{~mW}$, which was checked before irradiation using a Molectron PM5200 laser power meter. The reaction temperature was kept at $25{ }^{\circ} \mathrm{C}$ using a thermostated water bath. At regular time intervals during the runs, $0.2 \mathrm{~mL}$ samples of the gas in the tube were withdrawn with a gas-tight syringe and analyzed using a Shimadzu GC-8A gas chromatograph with a TC detector, equipped with MS-5A and Porapak-Q columns. The molar amount of carbon dioxide $\left(\mathrm{CO}_{2}\right)$ was calibrated considering the increase in pressure in the reaction tube consequent to the increased amount of gas-phase molecules. The kinetic runs were monitored for $80 \mathrm{~min}$ and repeated at least twice, in order to check their reproducibility. 


\subsection{Acetic acid decomposition-action spectra}

The photocatalytic decomposition of acetic acid in aerated liquid suspensions was investigated as a function of the irradiation wavelength, in quartz cells with a $c a$. 10.5$\mathrm{mL}$ volume. Each photocatalyst powder $(20 \mathrm{mg})$ was suspended in an aqueous solution $(2.0 \mathrm{~mL})$ containing 5.0vol.\% of acetic acid. The suspensions were stirred in the dark for $15 \mathrm{~min}$, to attain the adsorption equilibrium of the substrate on the photocatalyst surface, and then irradiated for 80 min under stirring. A 300-W xenon lamp (Hamamatsu Photonics C2578-02) was employed as irradiation source within a diffraction grating-type illuminator (Jasco CRM-FD), allowing the selection of the irradiation wavelength in the $300-520 \mathrm{~nm}$ range, with a full width at half-maximum intensity (FWHM) of $c a .17 \mathrm{~nm}$, irrespective of the selected irradiation wavelengths range, and a 20-nm step. The irradiation intensity, measured by a Hioki 3664 optical power meter, was in the $15-20 \mathrm{~mW}$ range. All other conditions were similar to those of photocatalytic activity tests under high-pressure mercury lamp irradiation. The action spectra of selected photocatalysts were also measured in the $370-460 \mathrm{~nm}$ range with a 10-nm step and a narrower FWHM, under otherwise identical experimental conditions.

The wavelength-dependent apparent quantum efficiency $\Phi_{\text {app }}$ was calculated as the ratio of the rate of photogenerated holes consumption and the flux of incident photons, by taking into account that 8 electrons (holes) are required according to the stoichiometry of the reaction: $\mathrm{CH}_{3} \mathrm{COOH}+2 \mathrm{O}_{2} \rightarrow 2 \mathrm{CO}_{2}+2 \mathrm{H}_{2} \mathrm{O}$.

\subsection{Acetaldehyde decomposition under polychromatic irradiation}

The photocatalytic oxidative decomposition of gaseous acetaldehyde in air was carried out in a closed cylindrical glass vessel, with a $357 \mathrm{~mL}$ volume and a $5.37 \mathrm{~cm}$ inner diameter. The photocatalyst powder $(20 \mathrm{mg})$ was uniformly spread on a glass plate $(1.0$ 
$\mathrm{cm} \times 1.0 \mathrm{~cm}$ ), placed on the bottom of the photoreactor, and pre-irradiated for $1 \mathrm{~h}$, in order to purify it from any adsorbed organic compound. Then gaseous acetaldehyde (0.36 mL, corresponding to $c a .0 .014 \mathrm{mmol}$ ) was injected into the photoreactor, containing ambient air, thus attaining a 1000-ppm initial acetaldehyde concentration. This injection was performed through a rubber septum, by using a lock-pressure syringe that allows the organic substrate addition at the desired pressure, 1 atm in our case.

In order to reach the adsorption equilibrium of the substrate on the photocatalyst surface, the system was then kept in the dark for $1 \mathrm{~h}$. Irradiation $(\lambda>290 \mathrm{~nm})$ was performed through a top window of the photoreactor using a $300-\mathrm{W}$ xenon lamp (ILC Technology CERMAX-LX300F). Acetaldehyde and $\mathrm{CO}_{2}$ concentrations were automatically measured at fixed time intervals using Agilent 3000 MicroGC.

The evolution of $\mathrm{CO}_{2}$ was also monitored during irradiation, in order to check if, in the presence of the different photocatalysts, acetaldehyde was effectively converted into $\mathrm{CO}_{2}$ according to the reaction: $\mathrm{CH}_{3} \mathrm{CHO}+(5 / 2) \mathrm{O}_{2} \rightarrow 2 \mathrm{CO}_{2}+2 \mathrm{H}_{2} \mathrm{O}$.

\section{Results and Discussion}

\subsection{Photocatalysts structure}

The main structural features, resulting from XRD, BET and XPS analyses, of the investigated series of undoped and doped $\mathrm{TiO}_{2}$ photocatalysts are collected in Table 1. The phase composition of all samples, obtained by Rietveld refinement of XRD data, clearly shows that doping inhibits the anatase-to-rutile transformation occurring when pure $\mathrm{TiO}_{2}$ is calcined at temperature above $500{ }^{\circ} \mathrm{C} .{ }^{40}$ This phase transformation is inhibited by the addition of $\mathrm{Ti}^{4+}$ complexing ions (e.g. sulphates, phosphates, fluorides),

reducing the condensation of spiral chains of rutile $\mathrm{TiO}_{6}$ octahedra. ${ }^{35}$ A similar argument has been employed to account for the full anatase composition of sulphur- 
doped anatase. ${ }^{25}$ The anatase crystallite dimensions $d_{\mathrm{A}}$, calculated using the Scherrer equation, ${ }^{43}$ clearly increased with increasing the calcination temperature for the same nominal dopant amount. This trend was accompanied by a decrease in specific surface area (SSA), as revealed by the BET analysis. Doping appears to be beneficial for obtaining materials with larger surface area, especially if calcined at relatively low temperature. The SSA of doped materials usually remained higher than that of pure $\mathrm{TiO}_{2}$, even after calcination at $700{ }^{\circ} \mathrm{C}$.

XPS analysis confirmed the presence of carbon, oxygen and titanium on the surface of all samples, ${ }^{40}$ with a $\mathrm{O} / \mathrm{Ti}$ ratio slightly higher than 2 , together with roughly constant surface amounts of nitrogen, on both undoped and doped samples (see Table 1). The XPS signal in the F 1s binding energy region consisted of only one band, peaking around $684 \mathrm{eV}$, due to surface fluoride ions. ${ }^{30,38}$ No XPS signal at $688 \mathrm{eV}$, assigned to substitutional ions in the $\mathrm{F}-\mathrm{TiO}_{2}$ lattice, could ever be detected, possibly always being below the detection limit of the XPS technique. The effective dopant/Ti molar ratio determined by quantitative XPS analysis, also reported in Table 1, was usually lower than the nominal value according to the synthesis of the different doped $\mathrm{TiO}_{2}$ series. Furthermore, the amount of fluorine ions physically adsorbed on the $\mathrm{TiO}_{2}$ surface usually decreased with increasing the calcination temperature.

\subsection{Photocatalytic activity tests under polychromatic irradiation}

\subsubsection{Liquid phase acetic acid photocatalytic oxidation under UV light}

The photocatalytic activity of doped $\mathrm{TiO}_{2}$ photocatalysts was first evaluated in the oxidative decomposition of acetic acid in aqueous suspension. The use of this substrate as photodegradation test molecule presents several advantages, apart from the main prerequisite that it does not absorb visible light: 1) the reaction is relatively simple, 
yielding $\mathrm{CO}_{2}$ with few intermediates; 2) because of the acidity of the suspension, $\mathrm{CO}_{2}$ is promptly removed from the liquid into the gas phase, where it can be easily determined.

The photocatalytic evolution of $\mathrm{CO}_{2}$ from suspensions containing acetic acid and either pure or doped $\mathrm{TiO}_{2}$ samples always occurred at constant rate, i.e. the rate obeyed the zero-order rate law. Thus, the photocatalytic activity of the investigated photocatalysts can be compared in terms of the zero-order rate constants of acetic acid photooxidation reported in Fig. 1.

We notice, first of all, that in the presence of undoped $\mathrm{TiO}_{2}$ the reaction proceeded at a lower rate with respect to that attained in the presence of moderately doped $\mathrm{TiO}_{2}$ 's. Moreover, with undoped $\mathrm{TiO}_{2}$ (D_0 series) the reaction rate decreased with increasing the calcination temperature, most probably as a consequence of the anatase-to-rutile transformation (Table 1).

Moderate doping increased the photocatalytic activity of $\mathrm{TiO}_{2}$ and this effect increased with increasing the calcination temperature of the photocatalyst, attaining a maximum value for moderately doped D_5_700 calcined at $700{ }^{\circ} \mathrm{C}$, in good agreement with the results of preliminary photocatalytic tests of formic acid photodecomposition. ${ }^{40}$ This may appear rather unusual, because the highest photoactivity was achieved with a photocatalyst characterized by a relatively low surface area and large mean particle sizes (see Table 1). Anyhow, doping seems to induce modifications of $\mathrm{TiO}_{2}$ that increase its photocatalytic activity and such effect is maximum for samples calcined at high temperature. Although surface fluorination of $\mathrm{TiO}_{2}$ is expected to retard the photocatalytic oxidation of carboxylic acids, as verified in the case of formic acid, ${ }^{44}$ this effect cannot be attributed exclusively to surface effects, i.e. to the slightly lower amount of surface fluorine detected on the surface of $\mathrm{D}-\mathrm{TiO}_{2}$ samples calcined at higher temperature (Table 1). On the other hand, excessive amount of dopant (D_25 series) 
could increase the extent of defects in the oxide structure, acting as recombination centres of photogenerated charge carriers, with a consequent decrease of the photocatalytic reaction rate.

The photoactivity data reported in Fig. 1 evidence that the best performing doped materials were more active than two pure anatase phase materials, labelled JRC-TiO-8 and A45, possessing very different specific surface areas (see Table 1), and also than commercial P25 $\mathrm{TiO}_{2}$ from Degussa (Evonik), often employed as a de-facto standard photocatalyst.

\subsubsection{Gas phase acetaldehyde photodecomposition under xenon lamp irradiation}

The photocatalytic degradation of acetaldehyde proceeded according to a first-order rate law. The first-order rate constants for $\mathrm{CH}_{3} \mathrm{CHO}$ degradation on doped and commercial photocatalysts can be compared in Fig. 2. They were obtained from the gas phase $\mathrm{CH}_{3} \mathrm{CHO}$ concentration vs. time profiles, neglecting the amount of substrate adsorbed on the photocatalyst surface. This kinetic behaviour is compatible with a diffusionlimited reaction, with $\mathrm{CH}_{3} \mathrm{CHO}$ surface concentration always being close to zero, because substrate molecules undergo oxidation as soon as they come in contact with the irradiated photocatalyst surface. Under such conditions the diffusion rate, and consequently the overall reaction rate, is proportional to the substrate concentration in the gas phase. ${ }^{45}$ Furthermore, the diffusion rate of the substrate is expected to increase with increasing the photocatalyst surface area. In fact, if the thickness of the diffusion layer is negligibly small, the diffusion cross section almost coincides with the surface area, and a correlation between the photocatalytic reaction rate and the specific surface area of the photocatalyst is usually expected..$^{45}$ 
However, by considering the first-order rate constant values reported in Fig. 2, we notice, rather surprisingly, that this kind of relation does not apply in the case of our doped $\mathrm{TiO}_{2}$ photocatalysts. In fact, the general trend of reaction rate increase with increasing the calcination temperature obtained for doped $\mathrm{TiO}_{2}$ in both formic and acetic acid photocatalytic decomposition in the liquid phase was found also in this gasphase test reaction, with the highest photoactivity being achieved with samples characterized by low surface area and moderately doped D_5_700 being confirmed as the best performing photocatalyst. Opposite results would have been expected for this gas-solid phase test reaction, whose rate was demonstrated to be positively affected by photocatalysts' large surface areas, ensuring fast diffusion of the acetaldehyde and $\mathrm{O}_{2}$ reactants. ${ }^{45}$

Only doped $\mathrm{TiO}_{2}$ photocatalysts of the D_3 series showed in acetaldehyde decomposition (Fig. 2) an opposite photoactivity trend vs. the calcination temperature, with respect to that shown in acetic acid photooxidation (Fig. 1). In fact, within this series the rate of acetaldehyde decomposition slightly decreased with increasing the photocatalyst calcination temperature, most probably as a consequence of the anatase into rutile transformation. Both the very low rutile content of D_3_600 and D_3_700 and the decrease of SSA with increasing the calcination temperature of these samples (Table 1) concurred in reducing their overall photoefficiency. Anatase crystallites were shown to be highly photoactive in both the present reactions under aerated conditions, whereas a negative contribution of the rutile phase was demonstrated just in the case of gas phase acetaldehyde decomposition. ${ }^{45}$

\subsection{Action spectra analysis}

\subsubsection{Action spectra of acetic acid decomposition $(300-520 \mathrm{~nm}$ range)}


In order to better elucidate the origin of the enhanced photoactivity of doped materials and verify their possible activation in the visible region, the photooxidation of the transparent acetic acid substrate was systematically investigated as a function of the irradiation wavelength. The action spectra were first measured for the D_0, D_5 and D_12 series in the $300-520 \mathrm{~nm}$ range, with a $20-\mathrm{nm}$ wavelength step. The action spectra and the absorption spectra of selected photocatalysts, normalized to the highest $\Phi_{\text {app }}$ and absorption value, respectively, are compared in Fig. 3. For undoped and doped $\mathrm{TiO}_{2}$ samples calcined at high temperature, the onset wavelength of the action spectra was red-shifted compared with that of the absorption spectra. This is probably due to the relatively large FWHM of the light employed in photocatalytic runs compared to that used for absorption measurements ${ }^{45}$ and to the fact that at shorter wavelengths $\mathrm{TiO}_{2}$ absorbs more than at longer wavelengths in a given wavelengths range.

This effect was not observed in the case of doped $\mathrm{TiO}_{2}$ calcined at $500{ }^{\circ} \mathrm{C}$. In fact, as shown in Fig. 3, these full anatase photocatalysts, though exhibiting a small absorption at wavelengths longer than those typical of the $\mathrm{TiO}_{2}$ band gap absorption onset, did not show any appreciable photocatalytic activity under visible light irradiation. On the other hand, as better outlined in the following systematic analysis of action vs. absorption spectra, doped samples calcined at $700{ }^{\circ} \mathrm{C}$ were active also under irradiation at wavelengths longer than that of their band gap absorption onset (see D_5_700 and D_12_700 panels in Fig. 3).

The action spectra of acetic acid decomposition obtained in the presence of undoped $\mathrm{TiO}_{2}$ calcined at different temperature are shown in Fig. 4a. The apparent quantum efficiency in the 300-400 $\mathrm{nm}$ wavelengths range decreased with increasing the calcination temperature of these undoped materials, whereas their absorption spectra, 
reported in Fig 4b, exhibit exactly the opposite trend, i.e. a red-shifted band gap absorption with increasing the calcination temperature, due to the phase transition from anatase into rutile.

The results reported in Fig. 4 can be explained by assuming that the anatase phase is more photoactive than rutile in acetic acid decomposition. ${ }^{45}$ In fact, the flat-band potentials of $\mathrm{TiO}_{2}$ depend on its crystalline form, being at -0.16 and $0.04 \mathrm{~V}$ vs. NHE ( $\mathrm{pH} 0$ ) for anatase and rutile $\mathrm{TiO}_{2}$, respectively. In the case of photocatalytic oxidation reactions, such as acetic acid decomposition, photoexcited electrons are scavenged by molecular oxygen at the $\mathrm{TiO}_{2}$ surface, where one-electron reduction of $\mathrm{O}_{2}$ occurs. Considering that the $\mathrm{O}_{2} / \mathrm{HO}_{2}{ }^{\circ}$ potential is $-0.046 \mathrm{~V}$ vs. NHE, anatase, but not rutile, is expected to efficiently reduce $\mathrm{O}_{2}$ to $\mathrm{HO}_{2}$ under band gap excitation, resulting in the relatively higher photocatalytic activity of anatase in acetic acid decomposition. Furthermore, less active rutile in undoped D_0_600 and D_0_700 may also exert a so called 'inner filter' action, by absorbing a fraction of light which is no more available for anatase phase photoactivation. ${ }^{45,46}$

For doped samples the wavelength-dependent apparent quantum efficiency in acetic acid decomposition was found to vary with both the dopant content and the calcination temperature of the investigated photocatalysts. The action spectra reported in Fig 5, referring to samples containing different nominal dopant amounts (D_0, D_5 and D_12 series), all calcined at the highest temperature $\left(700{ }^{\circ} \mathrm{C}\right)$, showed that the apparent quantum efficiency of doped materials was higher with respect to that of undoped $\mathrm{TiO}_{2}$. This could be mainly ascribed to the full anatase phase composition of doped materials, whereas D_0_700 also contains rutile, which, as already mentioned, is expected to be less active in acetic acid photodecomposition. However, a higher amount of dopant (D_12 series) led to a lower apparent quantum efficiency, especially under UV 
irradiation (300-340 $\mathrm{nm})$, most probably as a consequence of the already mentioned enhanced recombination of electron-hole couples photoproduced in this region, due to the increased extent of defects in the oxide structure, acting as charge recombination centres. The action spectra trend reported in Fig. 5 is in line with the photoactivity trend obtained under full lamp emission in both liquid and gas phase oxidation reactions investigated in the present work (see Figs. 1 and 2, respectively).

The effect produced by the calcination temperature on the photoactivity of samples containing the same nominal dopant amount is enlightened by the action spectra of the D_5 series, collected in Fig. 6. Two different relative photoefficiency scales can be found, depending on the irradiation wavelength region. For $\lambda_{\text {irr }}<400 \mathrm{~nm}$ the photoactivity of doped samples slightly decreased with increasing the calcination temperature, whereas for $\lambda_{\text {irr }} \geq 400 \mathrm{~nm}$ the opposite trend was observed, i.e. the photoefficiency increased with increasing the calcination temperature of doped samples. The same wavelength-dependent photoactivity trend was also obtained for the action spectra of the D_12 series. This suggests that doping might produce beneficial effects in the photoactivity of samples calcined at relatively high temperature, with a general photoefficiency trend in this wavelengths region perfectly matching that achieved under full lamp emission.

On the basis of these intriguing results the photoactivity of selected photocatalyst series was investigated more in depth in a smaller wavelengths range, centred in the near UV-Vis region.

\subsubsection{Action spectra of acetic acid decomposition $(370-460 \mathrm{~nm}$ range}

The action spectra in the $370-460 \mathrm{~nm}$ range obtained with a $10-\mathrm{nm}$ wavelength step for the D_5, D_12 and D_25 doped series, collected in Fig. 7, clearly confirm that within 
each series of doped materials a progressively higher calcination temperature ensured a better apparent quantum efficiency in all this wavelengths region.

The most straightforward demonstration that a certain material is an effective photocatalyst consists in the resemblance of its action spectrum with its absorption spectrum. ${ }^{41,42}$ However, no appreciable and obvious similarity can be found by directly comparing the action spectra of doped samples reported in Fig. 7 with their absorption spectra reported in Fig. 8. In fact, all samples calcined at $500{ }^{\circ} \mathrm{C}$, especially if containing a relatively high dopant amount, absorb light at wavelengths longer than those typical of the $\mathrm{TiO}_{2}$ band gap absorption onset. However, this visible light absorption did not induce any appreciable activity in acetic acid photodecomposition in this irradiation wavelengths range. On the contrary, doped samples calcined at higher temperature $\left(600\right.$ and $\left.700{ }^{\circ} \mathrm{C}\right)$ do not exhibit any noticeable extra absorption with respect to undoped $\mathrm{TiO}_{2}$, but they show increased efficiency in acetic acid photooxidation in the $370-410 \mathrm{~nm}$ range. By comparing the absorption properties of our materials with their wavelength-dependent photocatalytic activity, a qualitative model was developed, which provides a reasonable interpretation of our apparently controversial results.

\subsection{Model for absorption and action spectra deconvolution}

\subsubsection{Absorption spectra deconvolution}

The absorption spectra of samples belonging to the same series, i.e. containing a fixed nominal dopant amount, were compared first, to highlight the effects of calcination temperature and evidence the presence of possible sub-bands, through a procedure of absorption spectra subtraction. As shown in the examples reported in Fig. 9 referring to the D_25 series, the absorption spectra of samples calcined at lower temperature were 
subtracted from those of samples calcined at higher temperature. As all doped samples, even if calcined at $700{ }^{\circ} \mathrm{C}$, consist of pure anatase phase, any artifact in the difference spectra due to rutile phase absorption can be excluded (vide infra).

The so-obtained difference absorption spectra (Fig. 9) invariantly consist of a positive part, labelled peak $\mathrm{A}$, in the near UV region and a negative part at longer wavelengths in the near visible region, which can be labelled as peak B. For each difference spectrum, labelled as curve $\mathrm{C}$ in the example reported in Fig. 10, a deconvolution of peaks A and B was then performed. Under the assumption that peak B appearing in the longer wavelengths side is symmetrically shaped, the profile of peak A was obtained after subtracting the so-obtained peak B from curve C. This procedure was applied to each difference absorption spectrum for each D_5, D_12 and D_25 series. Finally, by assuming that peak A and peak B are absent in the absorption spectrum of doped samples calcined at 500 and $700{ }^{\circ} \mathrm{C}$, respectively, within each series the contribution of peaks A and B to the absorption spectrum of each doped sample was finally calculated.

The so-obtained results, reported in Fig. 11, evidence that for each series of doped samples the contribution of peak B (with a maximum around $420 \mathrm{~nm}$ ) decreased with increasing the calcination temperature, while that of peak A (with a maximum around $365 \mathrm{~nm}$ ) increased. On the other hand, by comparing the contributions of peaks A and B to the absorption spectra of samples calcined at the same temperature, but containing different nominal dopant amounts, the maximum intensity of both peaks A and B was found to increase with increasing the nominal dopant amount within the D_5, D_12 and D_25 series (see for example Fig. 12). The maximum position of both peaks A and B was not affected either by the calcination temperature or by the dopant content. 
In contrast, different results were obtained if the same kind of spectral subtraction analysis was applied to the absorption spectra of the D_3 series. In this case sample D_3_700 calcined at $700{ }^{\circ} \mathrm{C}$ did not consist of pure anatase, but contained $\mathrm{ca}$. $7 \%$ of the rutile phase (Table 1). The contribution of the so-obtained peak A for D_3_700 is also included in Fig. 12: this extra absorption peak is clearly red-shifted with respect to peaks $\mathrm{A}$ of the other $\mathrm{D}-\mathrm{TiO}_{2}$ series and should be ascribed to the typical band gap absorption shift of the rutile phase with respect to the anatase phase. This confirms that peak A with a maximum at about $365 \mathrm{~nm}$ obtained for D_5, D_12 and D_25 series is originated by an absorption contribution different from that of the rutile phase.

The intensity of the absorption peak B of doped samples was found to linearly increase with increasing the amount of surface fluorine detected by XPS analysis (Table 1), with a higher slope for samples calcined at $500{ }^{\circ} \mathrm{C}$ than for those calcined at $600{ }^{\circ} \mathrm{C}$ (not shown). An analogous correlation could not be established for the maximum intensity of peak A.

\subsubsection{Action spectra deconvolution}

Aiming at ascertaining whether absorption peaks A and B are active in acetic acid decomposition, a subtraction procedure similar to that performed for the absorption spectra was carried out also for the action spectra recorded in the $370-460 \mathrm{~nm}$ range (Fig. 7). Thus, for each series of doped materials the action spectra of samples calcined at $500{ }^{\circ} \mathrm{C}$ were subtracted from those of samples calcined at 600 and $700{ }^{\circ} \mathrm{C}$. By this way the difference action spectra reported in Fig. 13 were obtained.

In the visible light region $(\lambda>420 \mathrm{~nm})$ the action spectra of doped samples calcined at 600 and $700{ }^{\circ} \mathrm{C}$ do not show any appreciable difference with respect to that of the sample with the same nominal dopant amount, calcined at $500{ }^{\circ} \mathrm{C}$. This demonstrates 
that absorption peak $\mathrm{B}$, which is particularly evident in the absorption spectra of photocatalysts calcined at $500{ }^{\circ} \mathrm{C}$, does not produce any photoactivity in acetic acid decomposition to $\mathrm{CO}_{2}$ under visible light.

On the contrary, doped samples calcined at 600 and $700{ }^{\circ} \mathrm{C}$ showed an increase of photocatalytic activity in the UVA region with a maximum slightly red-shifted with respect to the maximum of absorption peak A. Such photoactivity enhancement was higher for photocatalysts calcined at the highest temperature $\left(700{ }^{\circ} \mathrm{C}\right)$, i.e. for photocatalysts exhibiting the most intense absorption peak A, clearly demonstrating that peak $\mathrm{A}$ is active in acetic acid decomposition. No clear trend could be ascertained outside the experimental uncertainty for photocatalysts containing different nominal dopant amounts, calcined at the same temperature (see maximum $\Delta \Phi_{\text {app }}$ values in Fig. 13). High doping probably plays a role also on this effect, due to the formation of a higher concentration of charge recombination centres in the $\mathrm{TiO}_{2}$ lattice. Of course, this type of analysis was not performed at $\lambda<370 \mathrm{~nm}$, because in this wavelengths region the test reaction is mainly promoted by anatase band gap absorption.

By comparing the difference spectra reported in Figs. 11 and 13, we may thus conclude that doping $\mathrm{TiO}_{2}$ with $\mathrm{NH}_{4} \mathrm{~F}$, followed by high temperature calcination, extends anatase band gap absorption on the long wavelengths side (peak A) and that this absorption in the UVA region is photoactive in acetic acid decomposition, whereas absorption peak B, appearing at longer wavelengths, is inactive in this reaction.

\subsection{XPS analysis before and after etching}

Aiming at correlating absorption peaks $\mathrm{A}$ and $\mathrm{B}$ to the chemical composition of our doped $\mathrm{TiO}_{2}$ photocatalysts, a detailed XPS analysis of D_12_500 and D_12_700 was performed before and after etching with Ar ions. High resolution XPS spectra of 
D_12_500 in the $\mathrm{F} 1 \mathrm{~s}$ and $\mathrm{N}$ 1s binding regions are reported in Fig. 14 a and b, respectively. The XPS spectrum in the $\mathrm{N}$ 1s binding energy region is dominated by a rather broad signal with a maximum around $400 \mathrm{eV}$, typically assigned to different forms of interstitial nitrogen dopants. ${ }^{1,47-49}$ After etching a new component appeared, peaking at $397 \mathrm{eV}$, usually associated to substitutional nitrogen located on an oxygen lattice site. ${ }^{4,48,50}$ On the other hand, the F 1s XPS signal consisted of only one band peaking at $c a .684 \mathrm{eV}$, attributed to $\mathrm{F}^{-}$ions adsorbed on the photocatalyst surface, ${ }^{30,35,37}$ which decreased after etching. No signal located around $688 \mathrm{eV}$, originated from fluorine substituting oxygen in the $\mathrm{TiO}_{2}$ crystal lattice, ${ }^{30.34}$ appeared either before or after etching (Fig. 14a).

Similar results were obtained for the highly photoactive D_12_700 sample calcined at $700{ }^{\circ} \mathrm{C}$ (Fig. $14 \mathrm{c}$ and d). In this case the F 1s signal at $684 \mathrm{eV}$ was lower than in the high resolution XPS spectrum of the D_12_500 sample (Fig. 14c vs. Fig. 14a), indicating a lower amount of adsorbed fluorine. This signal almost completely disappeared after etching (Fig. 14c), i.e. the fluorine content in the bulk was below the detection limit of XPS analysis. Concerning the high resolution N 1s XPS signal, the component picking at $397 \mathrm{eV}$, increasing after etching and attributed to substitutional nitrogen, in Fig. 14d is even more evident than in Fig. 14b, confirming the presence of nitrogen in the photocatalyst bulk, also after calcination at $700{ }^{\circ} \mathrm{C}$.

These results exclude the possibility of detecting fluorine in bulk D- $\mathrm{TiO}_{2}$, especially in samples calcined at high temperature, whereas they confirm the persistence of nitrogen species in the $\mathrm{D}-\mathrm{TiO}_{2}$ structure of photocatalysts calcined at $700{ }^{\circ} \mathrm{C}$, even though this does not correspond to any absorption under visible light irradiation. Present results are in line with previous findings obtained by EPR analysis, ${ }^{40}$ revealing the persistence of nitrogen species within the $\mathrm{TiO}_{2}$ structure even after calcination at $700{ }^{\circ} \mathrm{C}$. 
In fact the EPR spectra of both D_5 and D_12 series were dominated by the 4-lines signal attributed to the photocatalytically inactive paramagnetic nitric oxide (NO) radical encapsulated in microvoids, which almost completely masked the possible presence of $\mathrm{Ti}^{3+}$ centres.

\subsection{Origin of absorption peaks $A$ and $B$}

XPS analysis clearly demonstrates that our $\mathrm{D}-\mathrm{TiO}_{2}$ photocatalysts contain both fluorine and nitrogen. Although the nominal N/F molar ratio in all samples was fixed to 1 , they most probably contained a higher amount of nitrogen with respect to fluorine, in line with the results recently obtained on similar systems. ${ }^{51}$ According to DFT calculations reported in the literature, ${ }^{47} \mathrm{~N}$-impurities give rise to localized states a few tenths of an electronvolt above the valence band and also greatly favour oxygen vacancies formation. Paramagnetic N-containing species, though being in concentration around three orders of magnitude lower than bulk and surface doping levels, ${ }^{49}$ were indicated as responsible for visible light absorption and for the photoinduced electron transfer to adsorbed electron scavengers, such as molecular oxygen. ${ }^{47}$ On the other hand, the main effect of fluorine doping was the retardation of transformation of the anatase phase into rutile, ${ }^{30,36}$ yielding a highly crystalline anatase phase also after calcination at $700^{\circ} \mathrm{C}$, according to HRTEM analysis. ${ }^{40}$ Substitutional $\mathrm{F}$ dopants induce the formation of $\mathrm{Ti}^{3+}$ species in the bulk of polycrystalline anatase, ${ }^{30}$ that introduce localized states in the band gap, some tenths of electronvolt below the conduction band, ${ }^{37}$ but do not induce absorption in the visible region. ${ }^{34-37}$ Finally, N-F co-doping produces a charge compensation between $p$-type $(\mathrm{N})$ and $n$-type $(\mathrm{F})$ dopant, which reduces the energy cost to dope the material. ${ }^{51}$ Consequently, a smaller number of oxygen defects are expected to be present in $\mathrm{N}-\mathrm{F}$ co-doped $\mathrm{TiO}_{2}$ with respect to $\mathrm{N}$-doped $\mathrm{TiO}_{2}$. 
Aiming at ascertaining the origin of extra absorption peaks $\mathrm{A}$ and $\mathrm{B}$, we first of all notice a strong similarity between the absorption features of D_X_500 samples (Fig. 8) and $\mathrm{N}$-doped $\mathrm{TiO}_{2}$ in the visible region. The 'long tail' absorption at $\lambda>400 \mathrm{~nm}$ of more of less pale yellow $\mathrm{N}$-doped samples is commonly attributed to nitrogen species of different dopant sources. ${ }^{1,47,52}$ Furthermore, the intensity of this visible light absorption increases with increasing the dopant amount and decreases with increasing the calcination temperature, with a trend identical to that observed for $\mathrm{N}$-doped $\mathrm{TiO}_{2}{ }^{48,53,54}$

Therefore peak B, being most evident in the absorption spectra of doped samples calcined at $500^{\circ} \mathrm{C}$ and decreasing in intensity with increasing the calcination temperature (see Figs. 8 and 11), can safely be attributed to nitrogen doping. ${ }^{34}$ However, no photoactivity in acetic acid decomposition corresponds to this absorption peak, a not totally unexpected result, because the holes generated by visible photons in intra band gap states of $\mathrm{N}$-doped $\mathrm{TiO}_{2}$, possibly due to their insufficient oxidizing power and/or low mobility, were already shown to be ineffective in oxidizing several substrates, ${ }^{54,55}$ for example formic acid. ${ }^{11}$

Concerning peak A, its evidence was obtained for the first time by the spectral subtraction analysis performed in the present study. At difference with respect to peak B, absorption peak $\mathrm{A}$ is active in acetic acid decomposition (see Figs. 11 and 13). We tried to ascertain if its intensity may be correlated to the amount of $\mathrm{Ti}^{3+}$ species detectable by EPR analysis, and with the possibly formed oxygen vacancies, but unfortunately this was not possible, because the EPR spectra of our $\mathrm{NH}_{4} \mathrm{~F}$-doped photocatalysts were dominated by the signal of photocatalytically inactive NO radicals. ${ }^{40}$ However, by taking into account that the intensity of peak $\mathrm{A}$, and the consequent activity in acetic acid decomposition, increased with increasing the photocatalyst calcination temperature, 
this absorption feature might be attributed to extrinsic absorption originated from surface oxygen vacancies or surface defects, ${ }^{35,36,56,57}$ whose formation is expected to be favoured by F-doping at high calcination temperature. Indeed, photoluminescence signals attributed to such features were reported to increase with increasing the calcination temperature of F-doped $\mathrm{TiO}_{2}$ materials, ${ }^{35}$ though the amount of oxygen defects in $\mathrm{N}-\mathrm{F}$ co-doped $\mathrm{TiO}_{2}$ is expected to be lower than in $\mathrm{N}_{-} \mathrm{TiO}_{2}{ }^{51}$ Recent calculations seem to indicate that the peak near the absorption edge of the imaginary part of the dielectric function of $\mathrm{TiO}_{2}$ shifts to lower energy upon F-doping. ${ }^{56}$ On the other hand, as peak A appears as an extra absorption on the longer wavelengths side of the band gap absorption itself, we cannot exclude that it might simply be a consequence of the higher crystallinity of $\mathrm{D}-\mathrm{TiO}_{2}$ samples calcined at higher temperature, with respect to those calcined at $500{ }^{\circ} \mathrm{C}$, resulting in a higher absorption capability, as originally proposed by Hattori et al. in the case of $\mathrm{F}$-doped $\mathrm{TiO}_{2} \cdot{ }^{58}$ This hypothesis can hardly be verified, because of the intrinsic difficulties of evaluating the effective amount of crystalline material in our photocatalysts. ${ }^{41}$

In order to provide a definitive attribution of absorption band A, enlightening an eventual role of nitrogen doping on photoactivity, and to better ascertain the origin of peak $\mathrm{B}$, together with possible synergistic effects due to the co-presence of $\mathrm{N}$ and $\mathrm{F}$ dopants, a series of F-doped $\mathrm{TiO}_{2}$ photocatalysts containing no nitrogen has now been synthesised and is presently under investigation.

\section{Acknowledgements}

Financial support from the Cariplo Foundation through the Project Development of Second Generation Photocatalysts for Energy and Environment is gratefully acknowledged. 


\section{References}

1 A. Fujishima, X. Zhang and D. A. Tryk, Surf. Sci. Rep., 2008, 63, 515.

2 X. Chen and S. S. Mao, Chem. Rev., 2007, 107, 2891.

3 A. L. Linsebigler, G. Q. Lu and T. Yates, Jr., Chem. Rev., 1995, 95, 735.

4 R. Asahi, T. Morikawa, T. Ohwaki, K. Aoki and Y. Taga, Science, 2001, 293, 269.

5 S. U. M. Khan, M. Al-Shahry and W. B. Ingler, Jr., Science, 2002, 297, 2243.

6 H. Irie, Y. Watanabe and K. Hashimoto, J. Phys. Chem. B, 2003, 107, 5483.

7 S. Sakthivel, M. Janczarek and H. Kisch, J. Phys. Chem. B, 2004, 108, 19384.

8 J. L. Gole, J. D. Stout, C. Burda, Y. Lou and X. Chen, J. Phys. Chem. B, 2004, 108, 1230.

9 X. Chen and C. Burda, J. Phys. Chem. B, 2004, 108, 15446.

10 G. R. Torres, T. Lindgren, J. Lu, C.-G. Granqvist and S.-E. Lindquist, J. Phys. Chem. B, 2004, 108, 5995.

11 M. Mrowetz, W. Balcerski, A. J. Colussi and M. R. Hoffmann, J. Phys. Chem. B, 2004, 108, 17269.

12 C. Di Valentin, G. Pacchioni, A. Selloni, S. Livraghi and E. Giamello, J. Phys. Chem. B, 2005, 109, 11414.

13 K. Nishijima, B. Ohtani, X. Yan, T. Kamai, T. Chiyoya, T. Tsubota, N. Murakami and T. Ohno, Chem. Phys., 2007, 339, 64.

14 S. Sakthivel and H. Kisch, Angew. Chem., Int. Ed., 2003, 42, 4908.

15 T. Tachikawa, S. Tojo, K. Kawai, M. Endo, M. Fujitsuka, T. Ohno, K. Nishijima, Z. Miyamoto and T. Majima, J. Phys. Chem. B, 2004, 108, 19299.

16 B. Neumann, P. Bogdanoff, H. Tributsch, S. Sakthivel and H. Kisch, J. Phys. Chem. $B, 2005,109,16579$.

17 J. H. Park, S. Kim and A. J. Bard, Nano Lett., 2006, 6, 24. 
18 W. Zhao, W. Ma, C. Chen, J. Zhao and Z. Shuai, J. Am. Chem. Soc., 2004, 126, 4782.

19 H. Geng, S. Yin, X. Yang, Z. Shuai and B. Liu, J. Phys.: Condens. Matter, 2006, 18, 87.

20 D. Chen, D. Yang, Q. Wang and Q, Z. Jiang, Ind. Eng. Chem. Res., 2006, 45, 4110.

21 T. Umebayashi, T. Yamaki, H. Itoh and K. Asai, Appl. Phys. Lett., 2002, 81, 454.

22 T. Umebayashi, T. Yamaki, S. Yamamoto, A. Miyashita, S. Tanaka, T. Sumita and K. Asai, J. Appl. Phys., 2003, 93, 5156.

23 T. Ohno, M. Akiyoshi, T. Umebayashi, K. Asai, T. Mitsui and M. Matsumura, Appl. Catal., A, 2004, 265, 115.

24 J. C. Yu, W. Ho, J. Yu, J. H. Yip, P. K. Wong and J. Zhao, Environ. Sci. Technol., 2005, 39, 1175.

25 P. Periyat, S. C. Pillai, D. E. McCormack, J. Colreavy and S. J. Hinder, J. Phys. Chem. C, 2008, 112, 7644.

26 J. C. Yu, L. Zhang, Z. Zheng and J. Zhao, Chem. Mater., 2003, 15, 2280.

27 L. Lin, W. Lin, Y. Zhu, B. Zhao and Y. Xie, Chem. Lett., 2005, 34, 284.

28 X. Hong, Z. Wang, W. Cai, F. Lu, J. Zhang, Y. Yang, N. Ma and Y. Liu, Chem. Mater., 2005, 17, 1548.

29 G. Liu, Z. Chen, C. Dong, Y. Zhao, F. Li, G. Q. Lu and H.-M. Cheng, J. Phys. Chem. B, 2006, 110, 20823.

30 J. C. Yu, J. Yu, W. Ho, Z. Jiang and L. Zhang, Chem. Mater., 2002, 14, 3808.

31 K. Nukumizu, J. Nunoshige, T. Takata, J. N. Kondo, M. Hara, H. Kobayashi and K. Domen, Chem. Lett., 2003, 32, 196.

32 T. Yamaki, T. Umebayashi, T. Sumita, S. Yamamoto, M. Maekawa, A. Kawasuso and H. Itoh, Nucl. Instr. Meth. Phys. Res. B, 2003, 206, 254. 
33 D. Li, H. Haneda, S. Hishita and N. Ohashi, Chem. Mater., 2005, 17, 2588; D. Li, H. K. Haneda, S. Hishita and N. Ohashi, Chem. Mater., 2005, 17, 2596.

34 D. Li, N. Ohashi, S. Hishita, T. Kolodiazhnyi and H. Haneda, J. Solid State Chem., 2005, 178, 3293.

35 D. Li, H. Haneda, N. K. Labhsetwar, S. Hishita and N. Ohashi, Chem. Phys. Lett., 2005, 401, 579.

36 W. Ho, J. C. Yu and S. Lee, Chem. Commun., 2006, 10, 1115.

37 A. M. Czoska, S. Livraghi, M. Chiesa, E. Giamello, S. Agnoli, G. Granozzi, E. Finazzi, C. Di Valentin and G. Pacchioni, J. Phys. Chem. C, 2008, 112, 8951.

38 G. Wu, J. Wang, D. F. Thomas and A. Chen, Langmuir, 2008, 24, 3503.

39 S. Livraghi, K. Elghniji, A. M. Czoska, M. C. Paganini, E. Giamello and M. Ksibi, J. Photochem. Photobiol., A, 2009, 205, 93.

40 M. V. Dozzi, S. Livraghi, E. Giamello and E. Selli, Photochem. Photobiol. Sci., $2011,10,343$.

41 B. Ohtani, Chem. Lett. 2008, 37, 217.

42 E. Kowalska, O. O. Prieto-Mahaney, R. Abe and B. Ohtani, Phys. Chem. Chem. Phys., 2010, 12, 2344.

43 C. Bernardini, M. V. Dozzi, G. Cappelletti and E. Selli, J. Photochem. Photobiol. A: Chem., 2010, 211, 185.

44 M. Mrowetz and E. Selli, New J. Chem., 2006, 30, 108.

45 O. O. Prieto-Mahaney, N. Murakami, R. Abe and B. Ohtani, Chem. Lett., 2009, 38, 238.

46 T. Torimoto, N. Nakamura, S. Ikeda and B. Ohtani, Phys. Chem. Chem. Phys., 2002, 4, 5910 . 
47 C. Di Valentin, E. Finazzi, G. Pacchioni, A. Selloni, S. Livraghi, M. C. Paganini and E. Giamello, Chem. Phys., 2007, 339, 44.

48 X. Zhang, K. Udagawa, Z. Liu, S. Nishimoto, C. Xu, Y. Liu, H. Sakai, M. Abe, T. Murakami and A. Fujishima, J. Photochem. Photobiol. A: Chem., 2009, 202, 39.

49 F. E. Oropeza, J. Harmer, R. G. Egdell and R. G. Palgrave, Phys. Chem. Chem. Phys., 2010, 12, 960.

50 F. Amano, R. Abe and B. Ohtani, Trans. Mater. Res. Soc. Jpn., 2008, 33, 173.

51 C. Di Valentin, E. Finazzi, G. Pacchioni, A. Selloni, S. Livraghi, A. M. Czoska, M. C. Paganini and E. Giamello, Chem. Mater., 2008, 20, 3706.

52 S.-K. Joung, T. Amemiya, M. Murabayashi and K. Itoh, Appl. Catal. A: General, 2006, 312, 20.

53 S. In, A. Orlov, F. García, M. Tikhov, D. S. Wright and R. M. Lambert, Chem. Commun., 2006, 4236.

54 Q. Wang, C. Chen, W. Ma, H. Zhu and J. Zhao, Chem. Eur. J., 2009, 15, 4765.

55 R. Nakamura, T. Tanaka and Y. Nakato, J. Phys. Chem. B, 2004, 108, 10617.

56 H. Yang and X. Zhang, J. Mater. Chem., 2009, 19, 6907.

57 V.N. Kuznetsov and N. Serpone, J. Phys. Chem. B, 2006, 110, 25203.

58 A. Hattori, K. Shimoda, H. Tada and S. Ito, Langmuir, 1999, 15, 5422. 
Table 1. Phase composition and crystallite dimensions, $d_{\mathrm{A}}$, obtained from XRD analysis, by assuming the absence of amorphous phase; specific surface area (SSA), obtained from BET analysis; and surface F/Ti and N/Ti molar ratios, obtained from XPS analysis of the investigated photocatalysts series.

\begin{tabular}{|c|c|c|c|c|c|c|c|c|}
\hline Sample & $\begin{array}{c}\text { dopant/Ti } \\
\text { molar ratio } \\
(\%)\end{array}$ & $\begin{array}{c}\text { anatase } \\
(\%)\end{array}$ & $\begin{array}{c}\text { brookite } \\
(\%)\end{array}$ & $\begin{array}{c}\text { rutile } \\
(\%)\end{array}$ & $\mathbf{d}_{\mathbf{A}} / \mathbf{n m}$ & $\mathrm{SSA} / \mathrm{m}^{2} \mathrm{~g}^{-1}$ & $\begin{array}{c}\text { surface } \\
\text { molar F/Ti } \\
(\%)\end{array}$ & $\begin{array}{c}\text { surface } \\
\text { molar } \mathrm{N} / \mathrm{Ti} \\
(\%)\end{array}$ \\
\hline $\mathrm{P} 25$ & & 80 & - & 20 & 25 & 50 & & \\
\hline A45 & & 100 & - & - & 35 & 45 & & \\
\hline JRC-TiO-8 & & 100 & - & - & 4 & 338 & & \\
\hline D_0_500 & 0 & 99 & 1 & - & 15 & 15 & - & 2.8 \\
\hline D_0_600 & 0 & 90 & - & 10 & 32 & 9 & - & 2.8 \\
\hline D_0_700 & 0 & 38 & - & 62 & 65 & 7 & - & 3.0 \\
\hline D_3_500 & 3 & 98 & 2 & - & 16 & 65 & n.d. & n.d. \\
\hline D_3_600 & 3 & 97 & - & 3 & 32 & 32 & n.d. & n.d. \\
\hline D_3_700 & 3 & 93 & - & 7 & 40 & 22 & n.d. & n.d. \\
\hline D_5_500 & 5 & 98 & 2 & - & 13 & 63 & 6.0 & 2.9 \\
\hline D_5_600 & 5 & 100 & - & - & 44 & 31 & 4.3 & 2.6 \\
\hline D_5_700 & 5 & 99 & - & 1 & 49 & 16 & 3.7 & 2.9 \\
\hline D_12_500 & 12 & 100 & - & - & 19 & 43 & 7.1 & 2.9 \\
\hline D_12_600 & 12 & 100 & - & - & 33 & 23 & 5.0 & 3.0 \\
\hline D_12_700 & 12 & 99.5 & - & 0.5 & 48 & 12 & 4.4 & 4.2 \\
\hline D_25_500 & 25 & 100 & - & - & 19 & 39 & 9.6 & 3.4 \\
\hline D_25_600 & 25 & 100 & - & - & 47 & 15 & 6.5 & 3.3 \\
\hline D_25_700 & 25 & 100 & - & - & 110 & 8 & 11.5 & 2.6 \\
\hline
\end{tabular}

n.d. $=$ not determined 


\section{Figure Captions}

Fig. 1 Zero-order rate constants of $\mathrm{CO}_{2}$ photocatalytic evolution during acetic acid decomposition under polychromatic irradiation on commercial $\mathrm{TiO}_{2}$ photocatalysts and on doped $\mathrm{TiO}_{2}$ photocatalysts containing different dopant amounts and calcined at different temperature.

Fig. 2 First-order rate constants of $\mathrm{CH}_{3} \mathrm{CHO}$ photodegradation under xenon lamp irradiation on photocatalysts containing different dopant amounts and calcined at different temperature.

Fig. 3 Action spectra of acetic acid decomposition (full circles) and absorption spectra (dashed lines) of selected photocatalysts.

Fig. 4 a) Action spectra of acetic acid decomposition and b) absorption spectra of undoped $\mathrm{TiO}_{2}$ calcined at different temperature.

Fig. 5 Action spectra of acetic acid decomposition obtained in the presence of undoped (D_0) and differently doped samples (D_5 and D_12), all calcined at $700{ }^{\circ} \mathrm{C}$.

Fig. 6 Action spectra of acetic acid decomposition obtained in the presence of moderately doped samples (D_5 series) calcined at different temperature.

Fig. 7 Action spectra of acetic acid decomposition in the $370-460 \mathrm{~nm}$ wavelengths range of the a) D_5, b) D_12 and c) D_25 doped $\mathrm{TiO}_{2}$ photocatalysts series.

Fig. 8 Absorption spectra of the a) D_5,b) D_12 and c) D_25 doped $\mathrm{TiO}_{2}$ series. 
Fig. 9 Difference absorption spectra calculated for the D_25 series: the absorption spectra of samples calcined at lower temperature were subtracted from those of samples calcined at higher temperature.

Fig. 10 Deconvolution of peaks A and B from the difference of the absorption spectra of samples D_25_700 and D_25_600.

Fig. 11 Contributions of peaks A and B in the absorption spectra of photocatalysts of the a) D_5,b) D_12 and c) D_25 series, calcined at different temperature.

Fig. 12 Contribution of peak A to the absorption spectra of doped samples calcined at $700{ }^{\circ} \mathrm{C}$. Only D_3_700 contains a low amount of the rutile phase.

Fig. 13 Difference action spectra of the a) D_5, b) D_12 and c) D_25 photocatalysts series. The action spectrum of each sample calcined at $500{ }^{\circ} \mathrm{C}$ was subtracted from those of samples calcined at higher temperature.

Fig. 14 High resolution XPS spectra of the F 1s (a and c) and the N 1s (c and d) binding energy regions of D_12_500 ( $\mathrm{a}$ and b) and D_12_700 (c and d) before (solid line) and after etching with Ar ions (dotted line). 


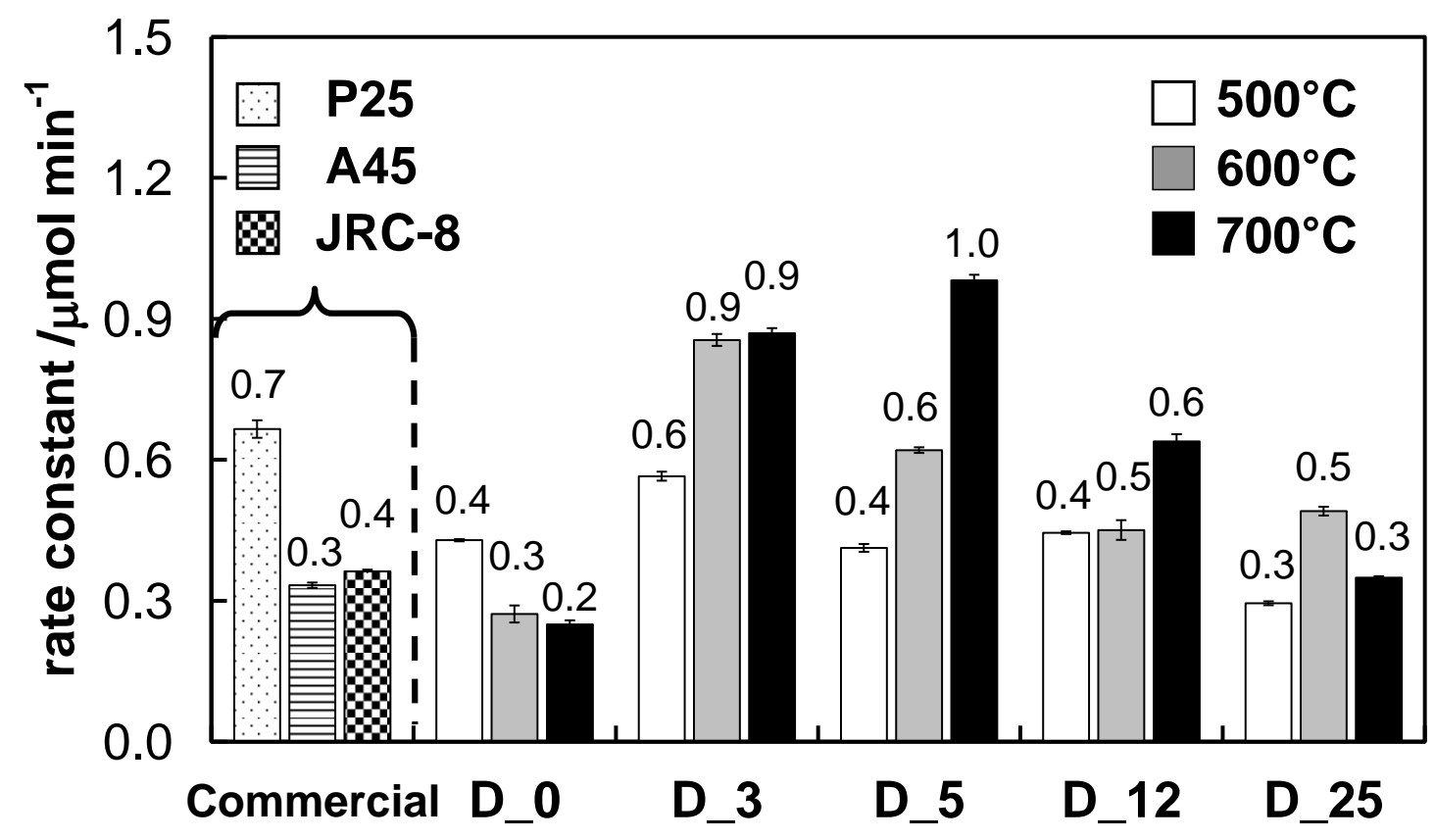

Fig. 1 Zero-order rate constants of $\mathrm{CO}_{2}$ photocatalytic evolution during acetic acid decomposition under polychromatic irradiation on commercial $\mathrm{TiO}_{2}$ photocatalysts and on doped $\mathrm{TiO}_{2}$ photocatalysts containing different dopant amounts and calcined at different temperature.

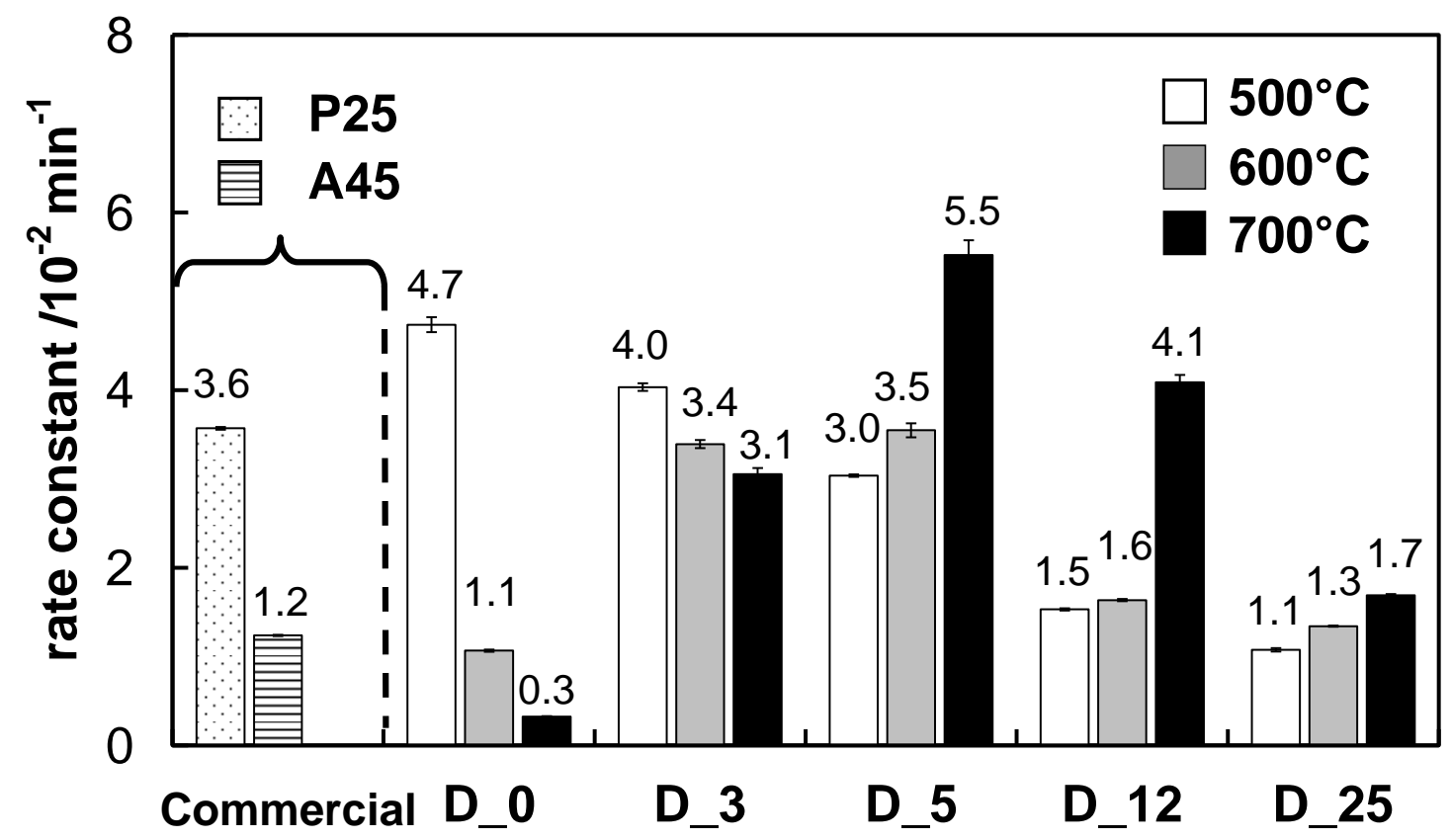

Fig. 2 First-order rate constants of $\mathrm{CH}_{3} \mathrm{CHO}$ photodegradation under xenon lamp irradiation on photocatalysts containing different dopant amounts and calcined at different temperature. 

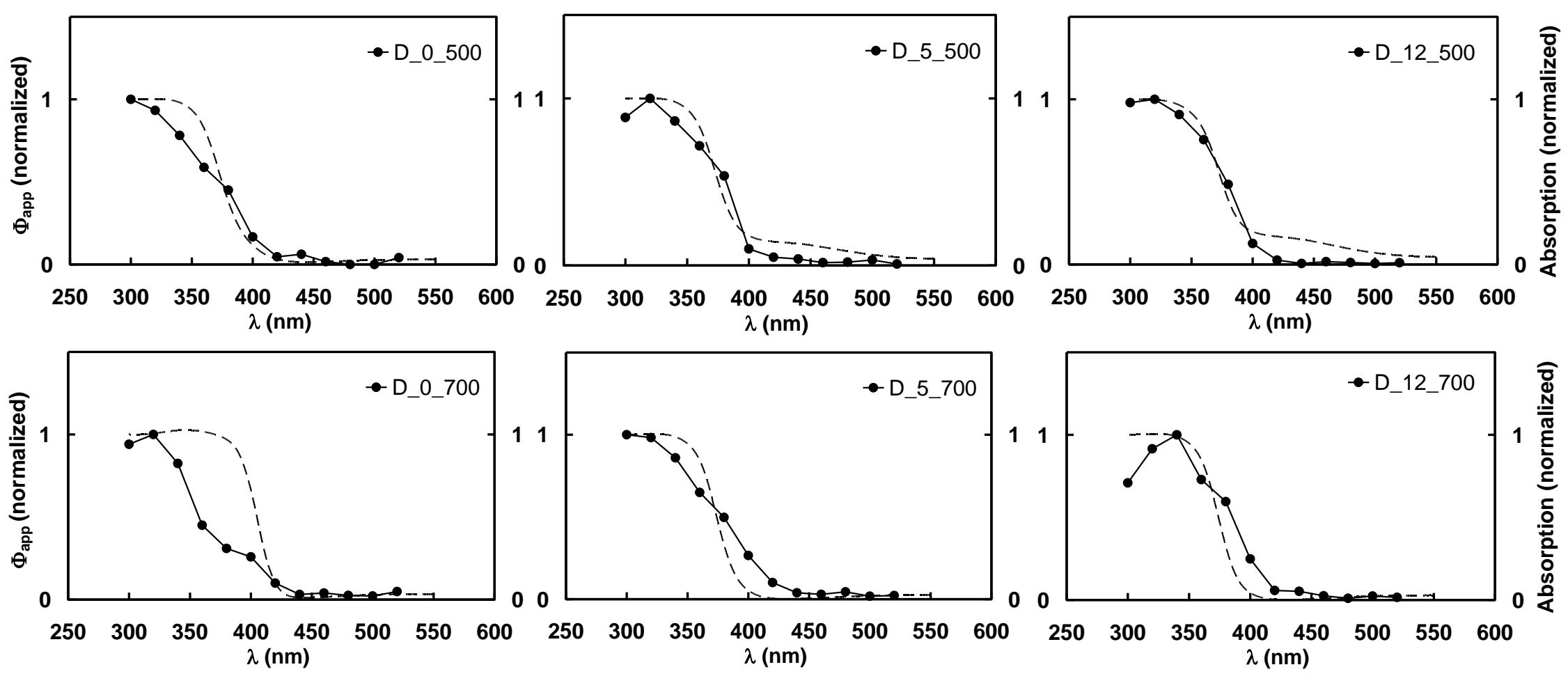

Fig. 3 Action spectra of acetic acid decomposition (full circles) and absorption spectra (dashed lines) of selected photocatalysts. 

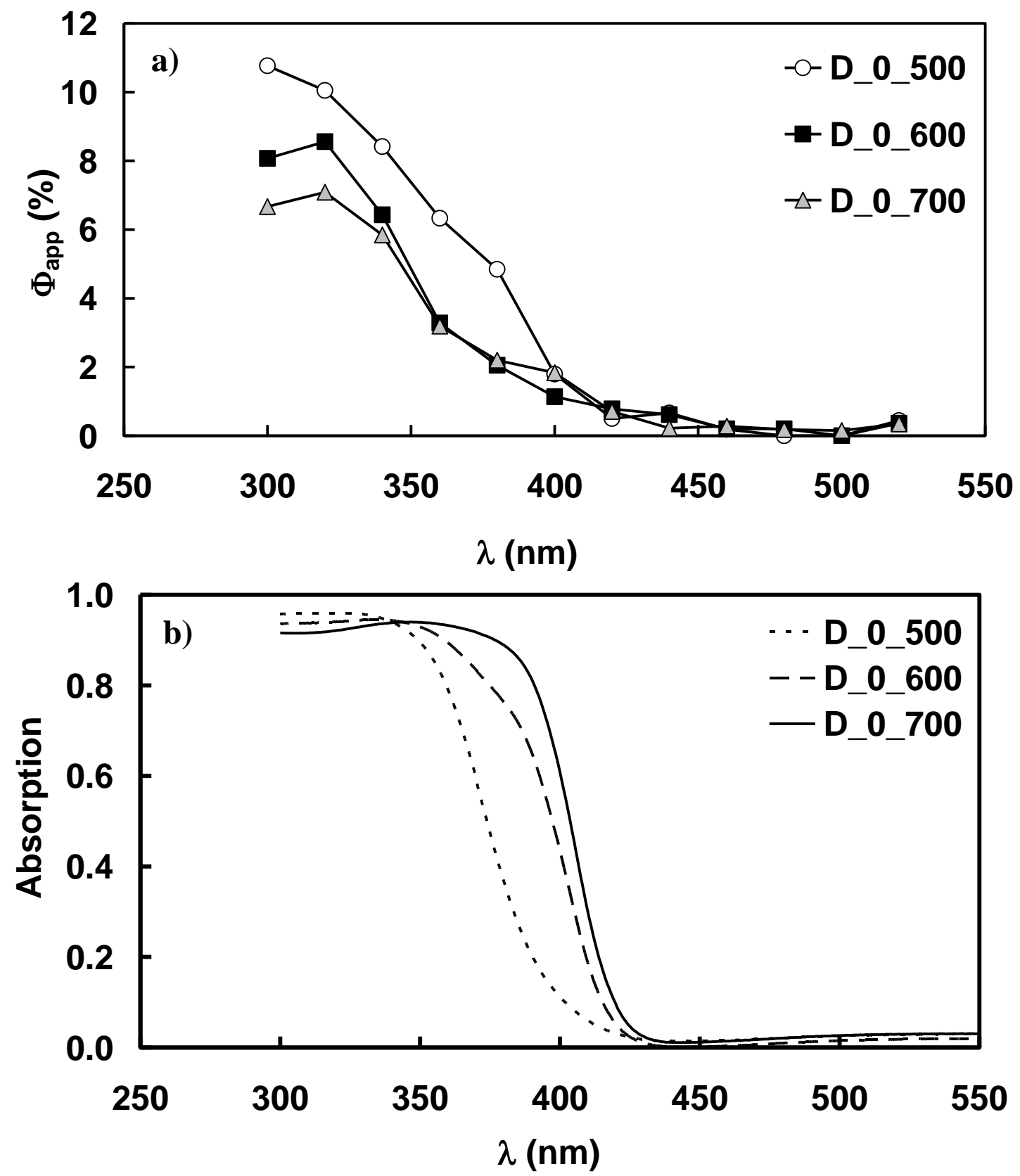

Fig. 4 a) Action spectra of acetic acid decomposition and b) absorption spectra of undoped $\mathrm{TiO}_{2}$ calcined at different temperature. 


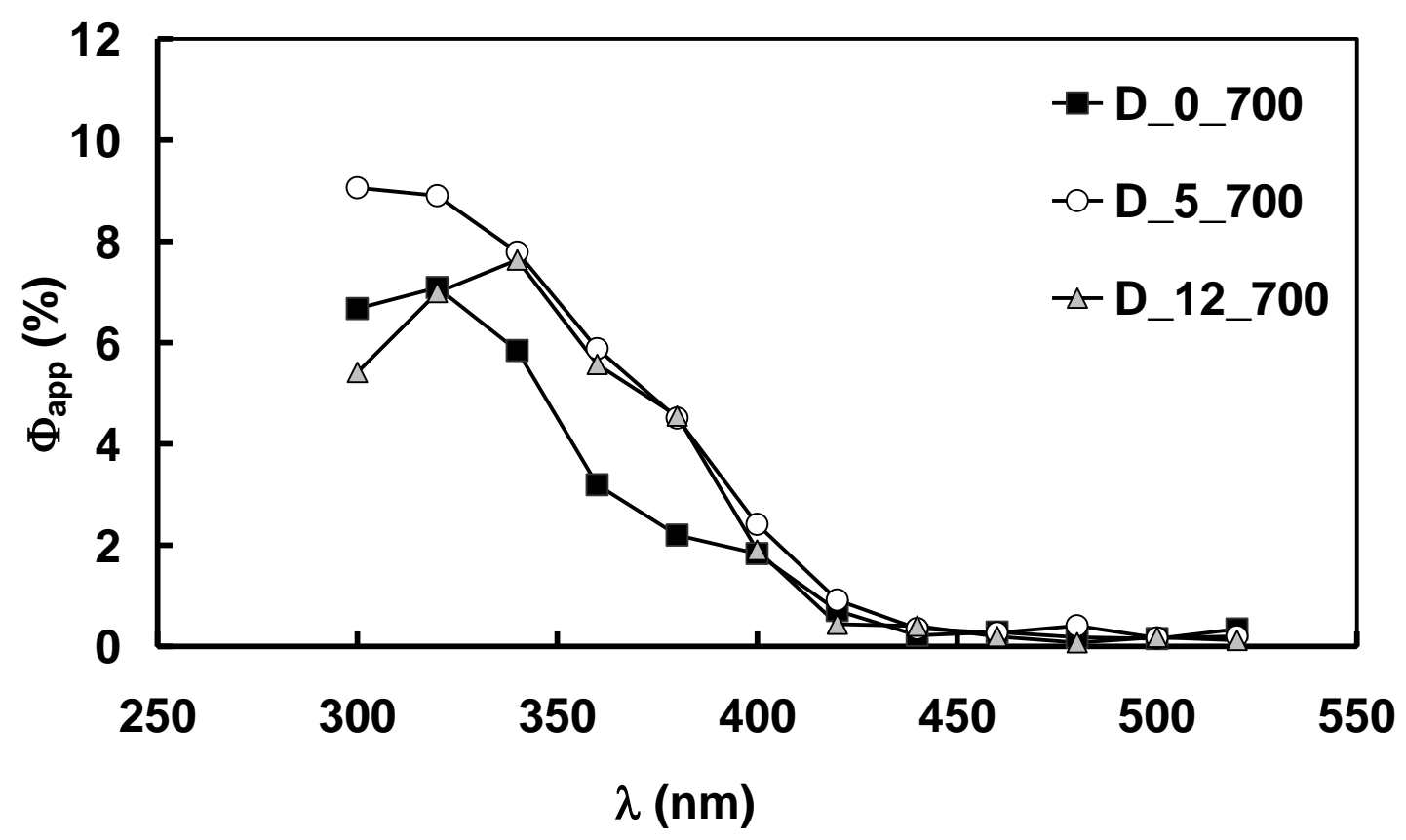

Fig. 5 Action spectra of acetic acid decomposition obtained in the presence of undoped (D_0) and differently doped samples (D_5 and D_12), all calcined at $700{ }^{\circ} \mathrm{C}$.

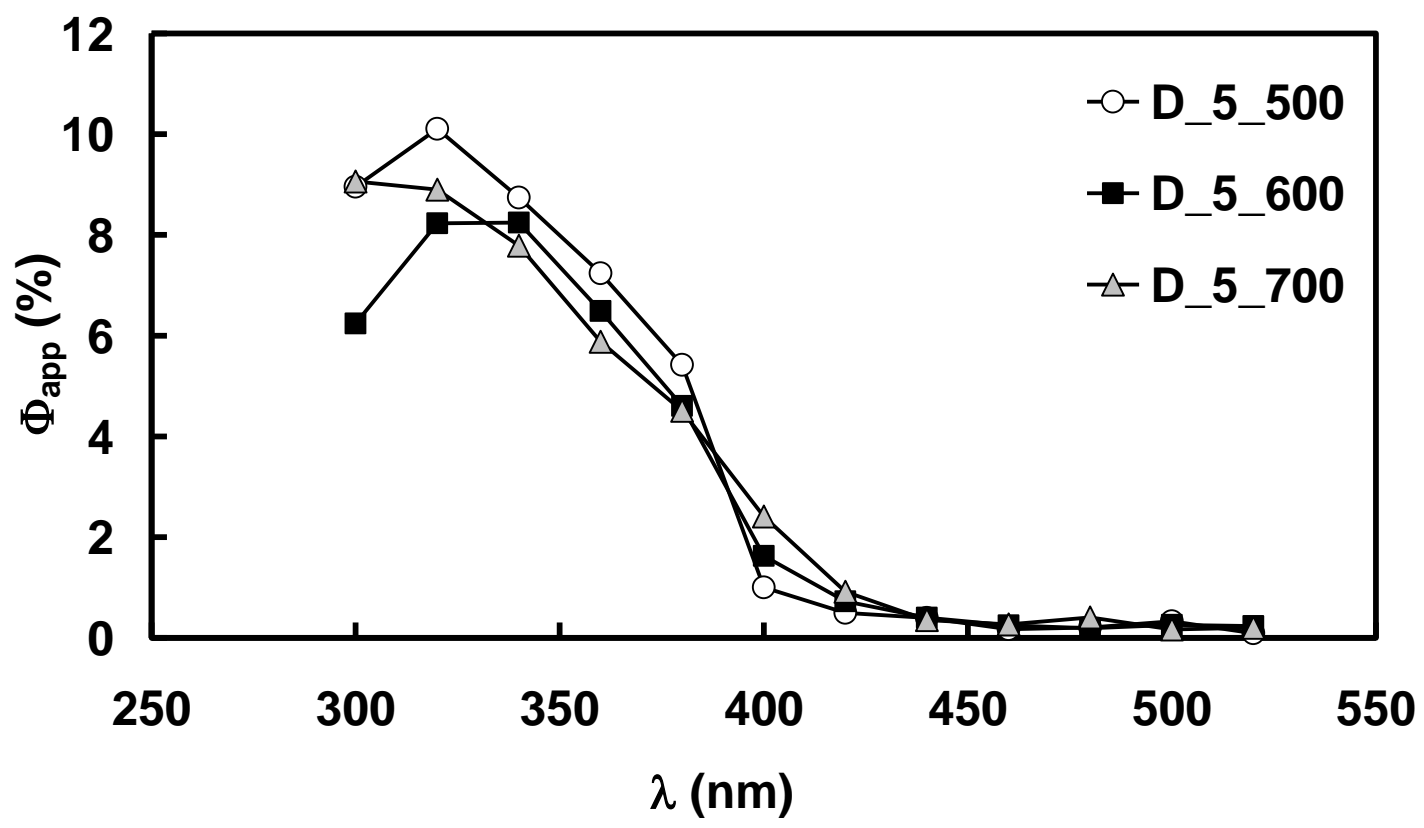

Fig. 6 Action spectra of acetic acid decomposition obtained in the presence of moderately doped samples (D_5 series) calcined at different temperature. 

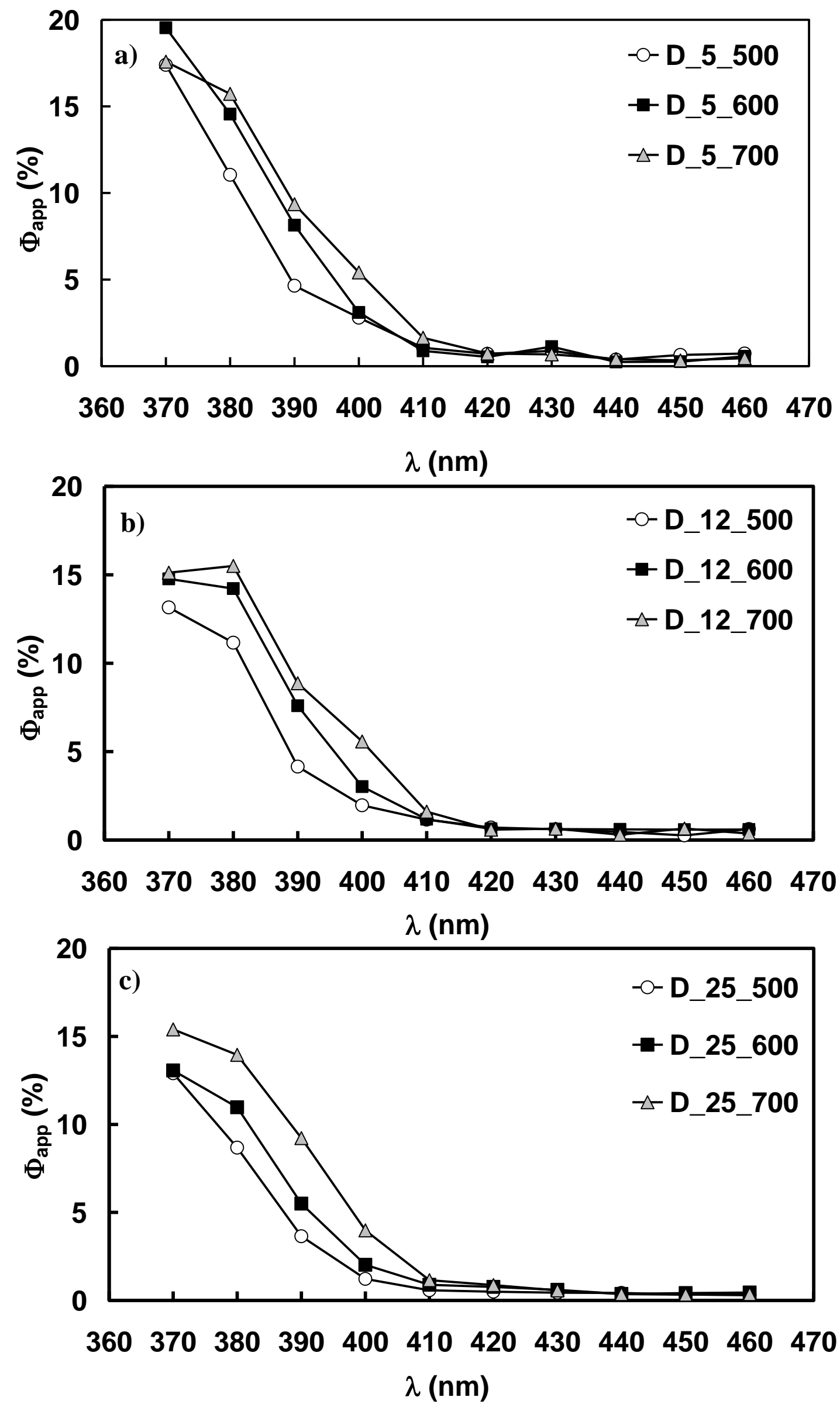

Fig. 7 Action spectra of acetic acid decomposition in the 370-460 nm wavelengths range of the a) D_5, b) D_12 and c) D_25 doped $\mathrm{TiO}_{2}$ photocatalysts series. 

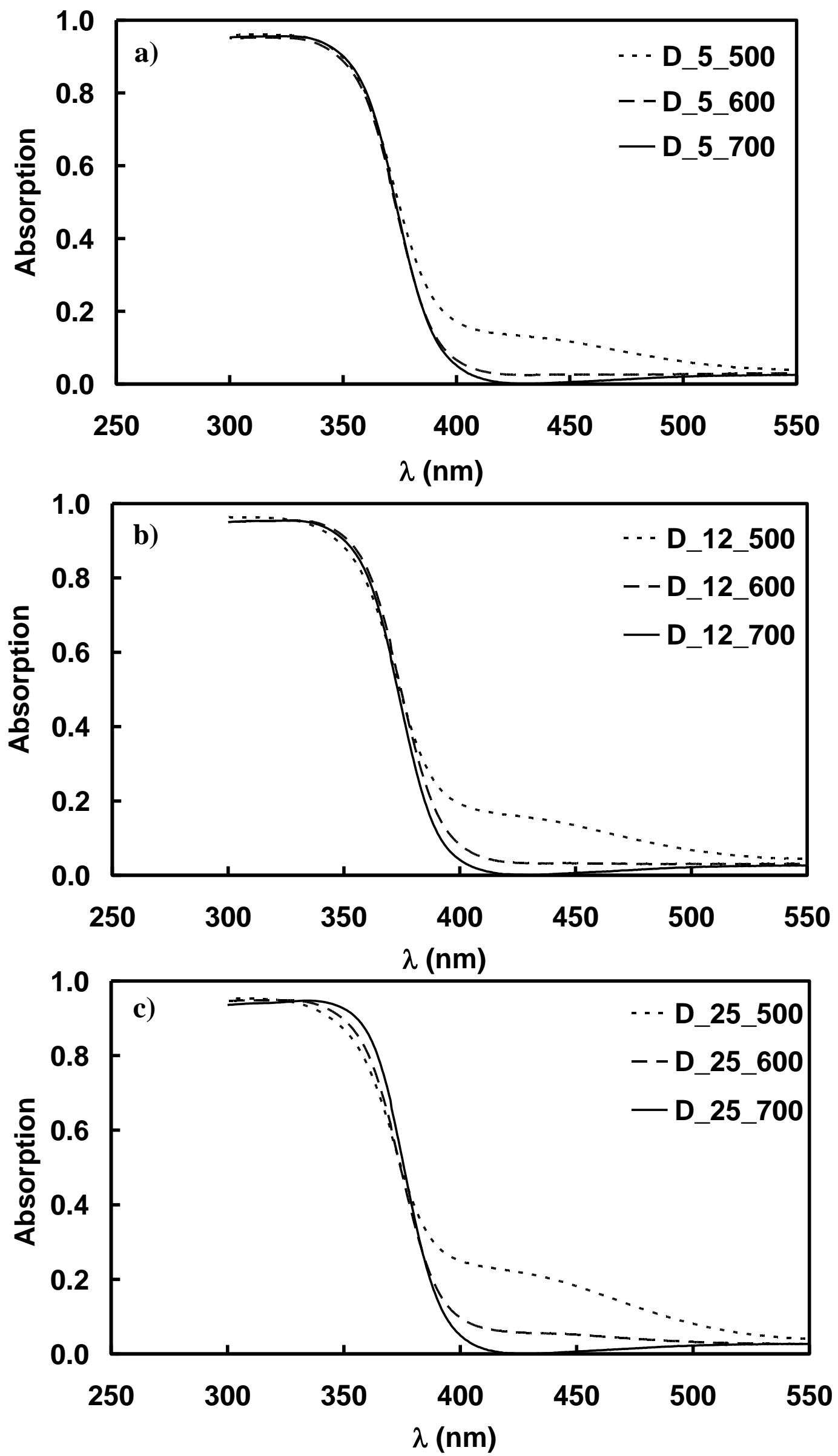

Fig. 8 Absorption spectra of the a) D_5, b) D_12 and c) D_25 doped $\mathrm{TiO}_{2}$ series. 


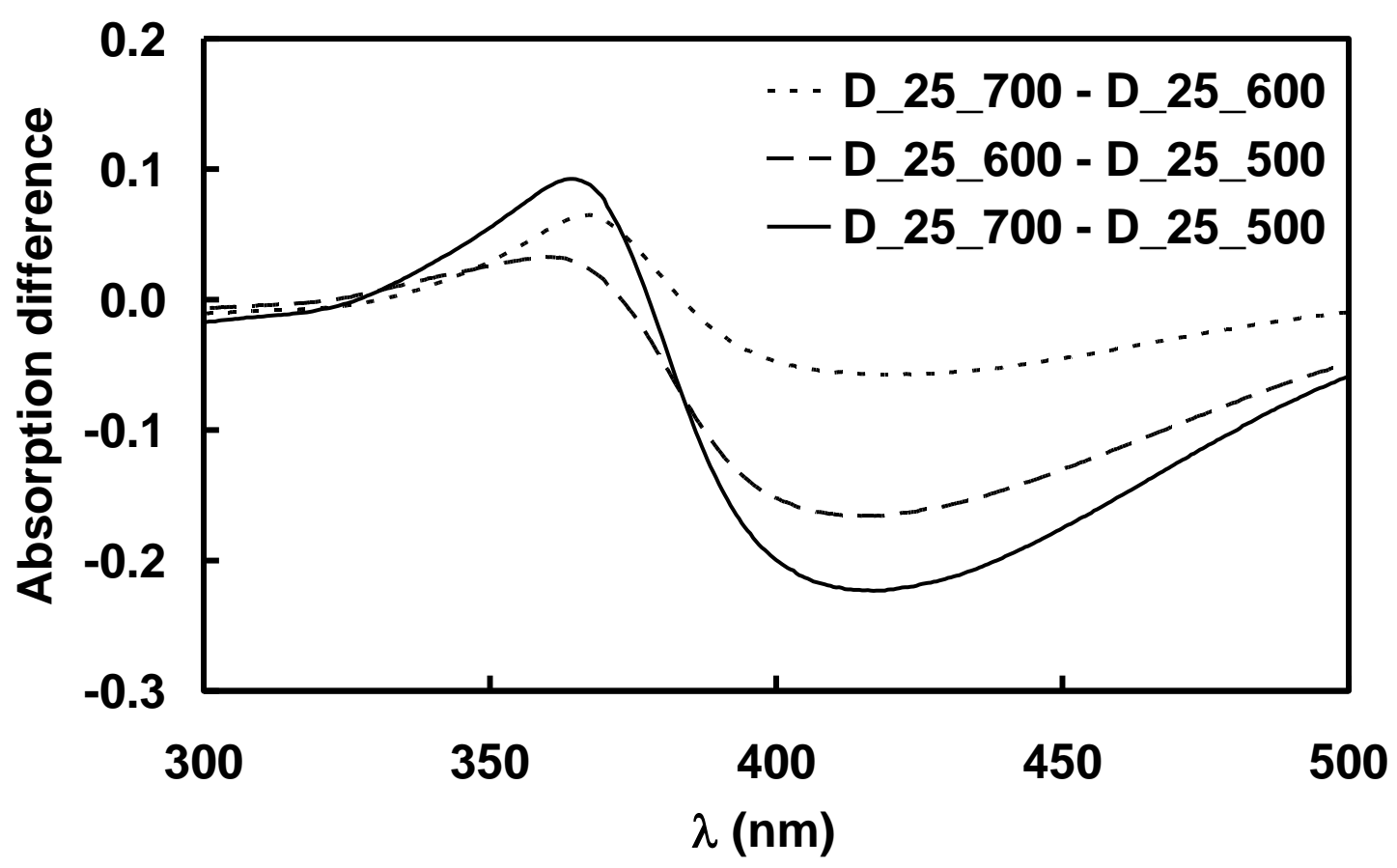

Fig. 9 Difference absorption spectra calculated for the D_25 series: the absorption spectra of samples calcined at lower temperature were subtracted from those of samples calcined at higher temperature.

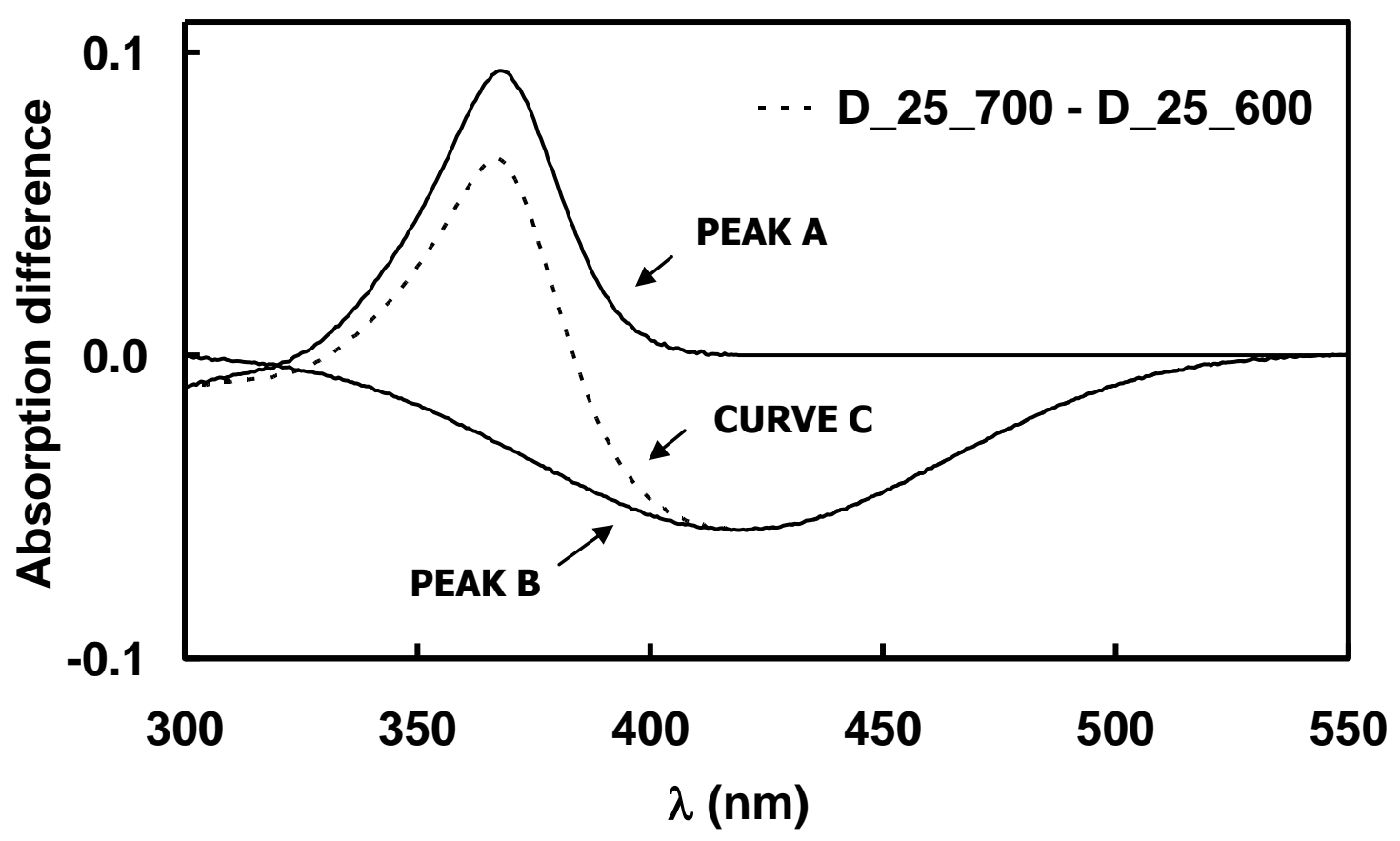

Fig. 10 Deconvolution of peaks A and B from the difference of the absorption spectra of samples D_25_700 and D_25_600. 

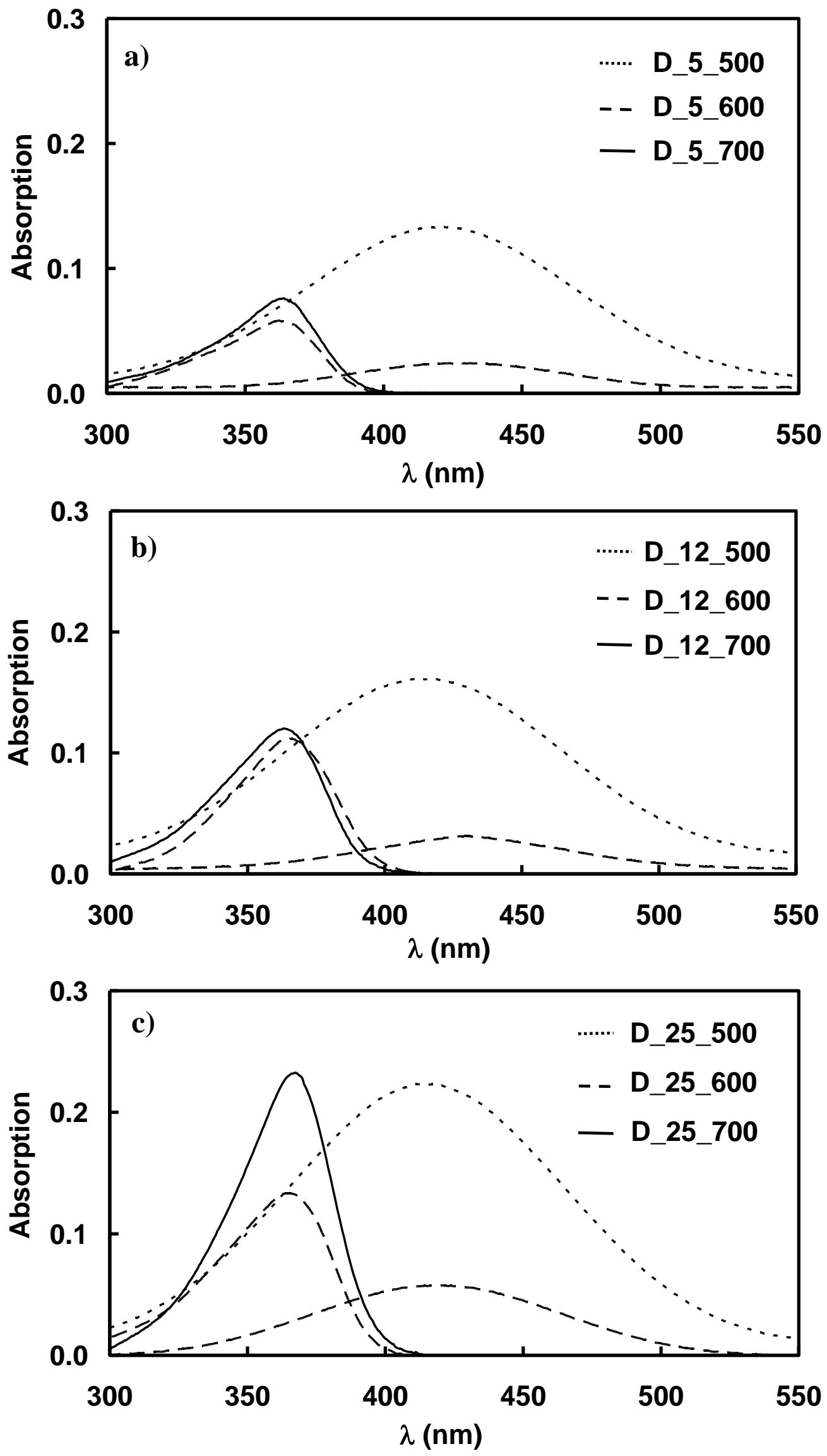

Fig. 11 Contributions of peaks $A$ and $B$ in the absorption spectra of photocatalysts of the a) D_5, b) D_12 and c) D_25 series, calcined at different temperature. 


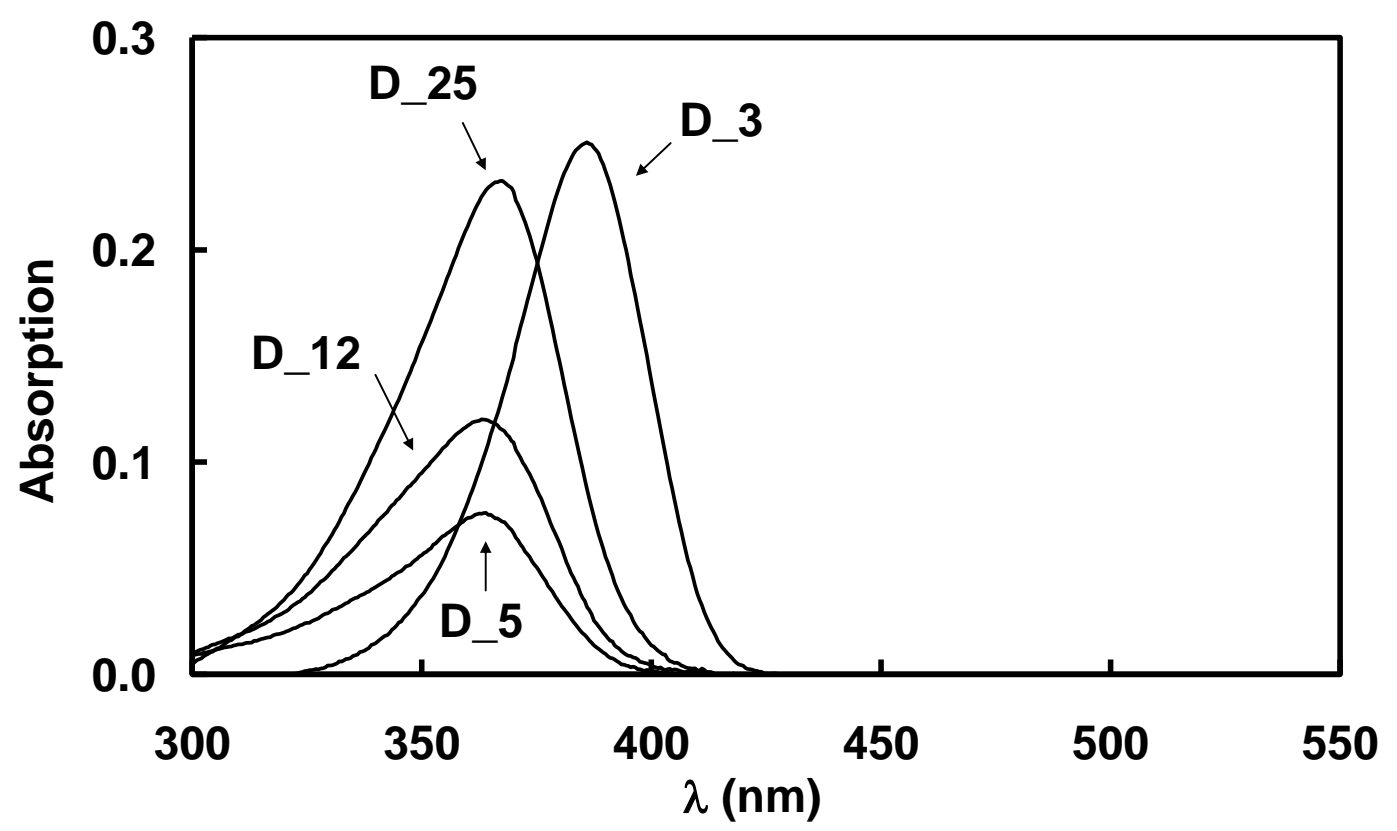

Fig. 12 Contribution of peak A to the absorption spectra of doped samples calcined at $700^{\circ} \mathrm{C}$. Only D_3_700 contains a low amount of the rutile phase. 

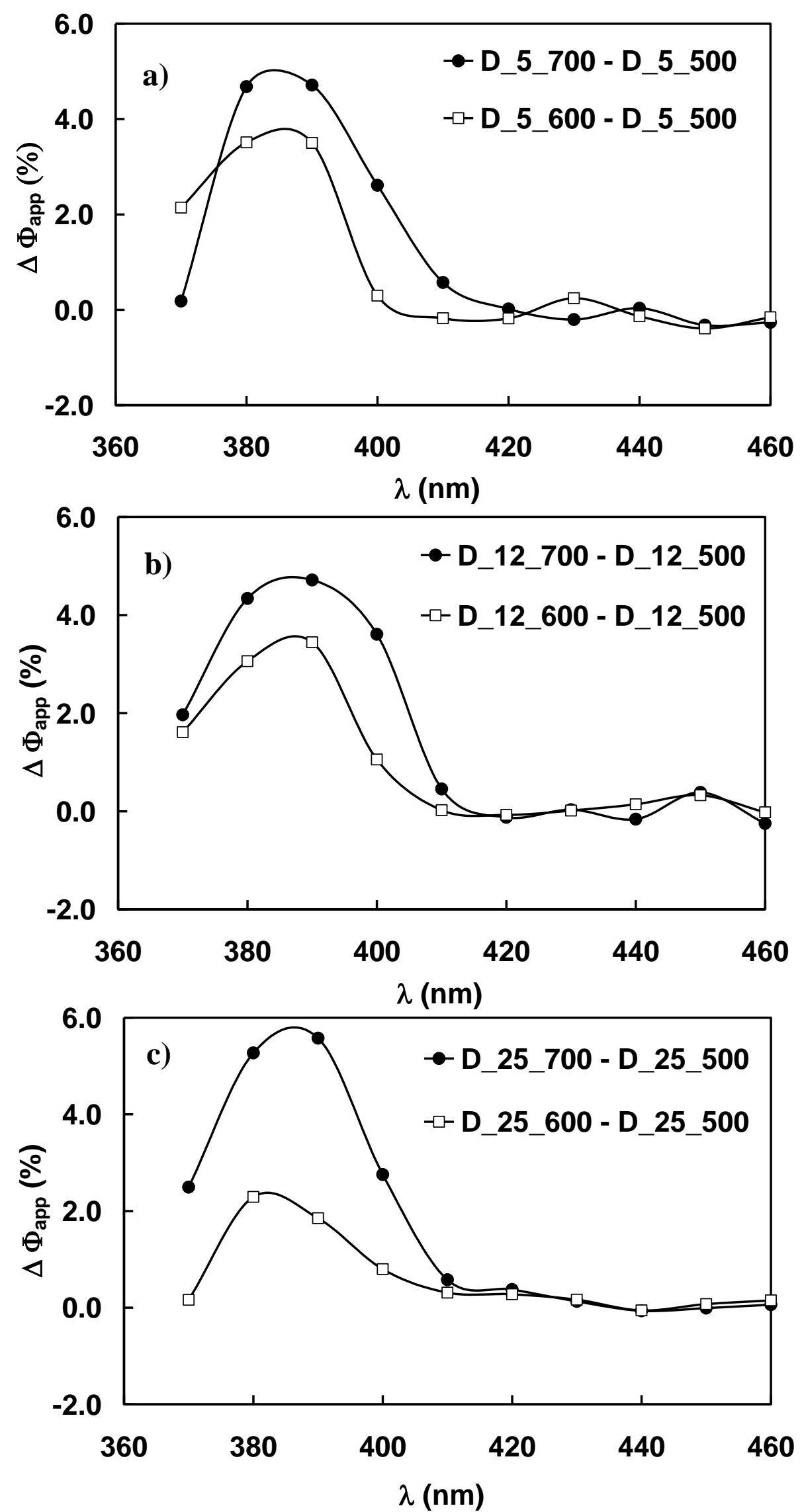

Fig. 13 Difference action spectra of the a) D_5, b) D_12 and c) D_25 photocatalysts series. The action spectrum of each sample calcined at $500{ }^{\circ} \mathrm{C}$ was subtracted from those of samples calcined at higher temperature. 

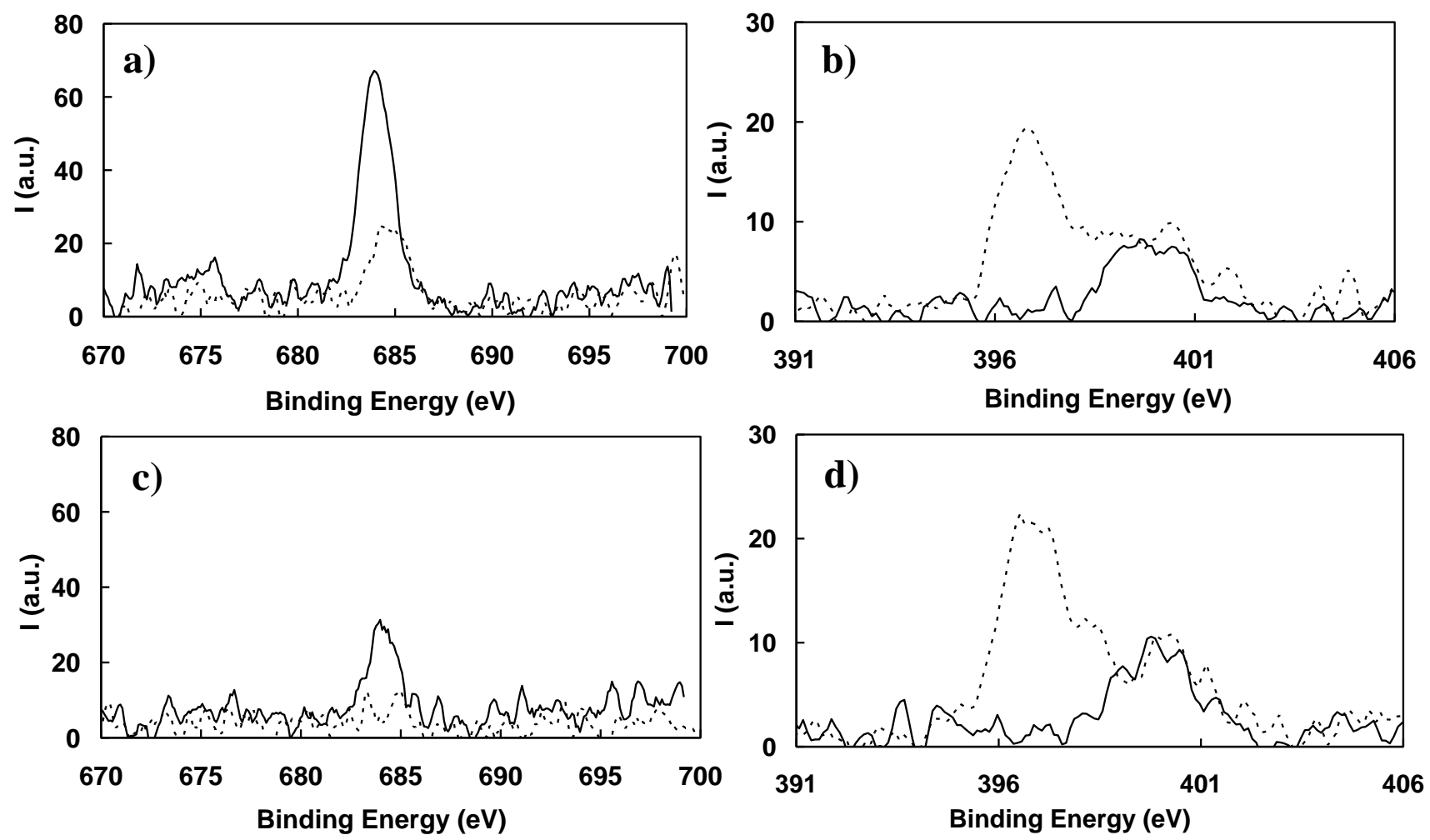

Fig. 14 High resolution XPS spectra of the F 1s (a and c) and the N 1s (c and d) binding energy regions of D_12_500 ( $\mathrm{a}$ and b) and D_12_700 ( $\mathrm{c}$ and d) before (solid line) and after etching with Ar ions (dotted line). 